\title{
A Comparative Study of Huff-n-Puff Gas and Solvent Injection in a Shale Gas Condensate Core
}

\author{
Sharanya Sharma and James J. Sheng*, Texas Tech University \\ *Corresponding author: james.sheng@ttu.edu, (806)834-8477
}

\begin{abstract}
A compositional modeling study is conducted to compare huff-n-puff solvent injection with gas injection in improving oil recovery from shale gas-condensate reservoirs. The solvents used are methanol and isopropanol, and gases are methane and ethane. The model represents a simple 8"X1" lab scale core model based on a published experimental work. The phase behavior data and relative permeability data are tuned to match the published lab data.

Simulation results are analyzed to compare the performance of four injection fluids - methane, ethane, methanol and isopropanol (IPA) based on the recovery of fluids in place in terms of barrel of oil equivalent within the same operation time. Comparisons were made for two reservoir fluids, Fluid A and Fluid B, with the latter having a higher liquid dropout. Recovery mechanisms are also studied for gases and solvents.

Ethane injection is a novel idea in this paper and proved to be the best injection fluid on accounts of higher as well as much faster recovery as compared to methane, methanol or isopropanol. This is attributed to ethane being a lighter fluid and aiding in revaporizing the condensate. While this is also true for methane, the most significant difference between the two is that ethane is also able to reduce overall dew point pressure of the mixture, ensuring lower injection volume and time for the same recovery factor.
\end{abstract}

\section{Introduction}

The phenomena of retrograde condensation can cause severe reduction in productivity of a gascondensate reservoirs. This occurs when the reservoir pressure falls below the dew-point pressure of the gas-condensate fluid system. Heavier and valuable hydrocarbon components condense from the gas phase causing blockage in the pores, restricting the gas flow path. This reduces both the productivity of the gas as well as the oil phase. The most important defining parameter in reduction of reservoir productivity is a critical condensate saturation (Bennion et al., 2001); if the saturation of the condensed hydrocarbon phase is less than this critical value it remains immobile and reduces the relative permeability of the flowing gas.

Reduction of gas productivity has also been reported to be severe for lean gas condensate reservoirs, specifically in the Arun field where productivity reduced by $50 \%$ for a $1.1 \%$ liquid dropout fluid system (Afidick et al., 1994). Coreflood experiments have demonstrated severe condensate blocking for both low and high permeability cores (Al-Anazi et al., 2002), however, this problem is compounded in low permeability formations (Wheaton and Zhang, 2000). 
While in conventional reservoirs a bank of condensate forms around the well, with condensate saturations decreasing away from the well as pressures increases further into the reservoir, for shale reservoirs we may expect condensate buildup in the fractures with condensate saturations reducing as we move into the stimulated rock volume area, and reservoir matrix adjacent to the fractures. This is where the immobile condensate phase maybe expected. Lab experiments showed a $90 \%$ decrease in gas relative permeability for propped fractures in conventional reservoir cores (Bang et. al., 2008).

Several mitigation methods have been practiced and researched for recovering gas and condensate from the reservoir. The most common is dry gas injection (Abel et al., 1970; Sheng, 2015; Sheng et al., 2016;) which helps maintain reservoir pressure above the dew point pressure of the reservoir and additionally, re-evaporate any condensate that has accumulated in the reservoir (Meng and Sheng, 2016; Meng et al., 2016). Other alternatives such as methane (AlAnazi et al., 2004), $\mathrm{CO}_{2}$ (Amini et al., 2011) and, nitrogen injection (Siregar et al., 1992) have been successfully tried. Methane huff-n-puff experiments have also shown good EOR potential in shale cores where condensate recovery was $52.7 \%$ after 8 cycles of methane huff-n-puff (Meng et al., 2015).

Apart from gas injection, chemical treatment for improving recovery from gas condensate reservoirs has been extensively researched. This can be broadly categorized into two parts solvent injection and surfactant application. Methanol flooding experiments have been conducted on both high permeability sandstone and low permeability limestone cores to treat condensate blockage where the relative permeability of gas improved significantly and condensate banking phenomena was delayed for some time (Al-Anazi et al., 2002). Methanol injection was also tried in the Hatter's Pond Field where enhanced flow period was observed for up to four months after the treatment increasing recovery by up to $50 \%$ for both gas and condensate (Al-Anazi et al., 2003). Extensive phase behavior experiments were done to understand the addition of methanol and isopropanol to synthetic gas-condensate mixtures (Bang et al., 2010). Isopropanol can solubilize more hydrocarbons compared to methanol and it does not partition into water unlike methanol. Addition of a solvent shifts the phase behavior of the fluid from the gas condensate region to a volatile region and the fluid thus exhibits a bubble point instead of a dew point pressure. This mechanism helps extract the liquid dropped-out as the entire system exits as a single phase liquid (Ayyalasomayajula et al., 2002).

This work presents a comparative study for application of four injection fluids to remediate condensate blockage- methane, ethane, methanol and isopropanol based on recovery factors of total barrel of equivalent (BOE) from a core-scale model. 


\section{Methodology}

\subsection{Model Description and Validation}

Published core flood experiments for a synthetic four component gas condensate fluid (Al-Anazi et al., 2003) were regenerated using Computer Modelling Group's (CMG) GEM simulations. This reservoir fluid is called Fluid $\mathrm{A}$ in this paper and its description is given in Table 1. AlAnazi conducted several experiments on high permeability sandstone and low permeability limestone cores to capture the dynamic accumulation of condensate buildup in a core, as the core pressure was reduced below the dew point pressure of the gas-condensate fluid. The inlet pressure was maintained at $3000 \mathrm{psi}$, which was above the dew point pressure of the gas, while the outlet pressure was maintain at 1200 psi. Single phase gas was injected at a constant flow rate. The gas flashed out into two phase gas and condensate upon entering the core. Al-Anazi measured the pressure drop across the core to determine the condensate buildup and plotted this as a function of the pore volume of hydrocarbons injected into the core.

A low flow rate experiment from Al-Anazi's work was used to history match our model. In this experiment, gas was injected at a constant flow rate of $2 \mathrm{cc} / \mathrm{hr}$. The pressure drop vs. pore volume injected plot is shown in Figure 1. The figure shows two sets of data - Al-Anazi's experimental data and a simulation match of his experiment as generated by Rai et al. (2003). Rai and Al-Anazi concluded in their work that simulating high flow rate experiments was difficult due to non-equilibrium effects. As the flow rate increased, more pore volume of gas had to be injected to achieve steady state flow in experiments. This was attributed to a stripping effect of the condensate by gas and more pore volumes required for condensate to accumulate and reach its moveable critical condensate saturation. Contrariwise, simulations of high flow rate experiments showed that less pore volume was required to reach the same steady state pressure drop. For this reason, we chose the low flow rate experiment to validate our model. 


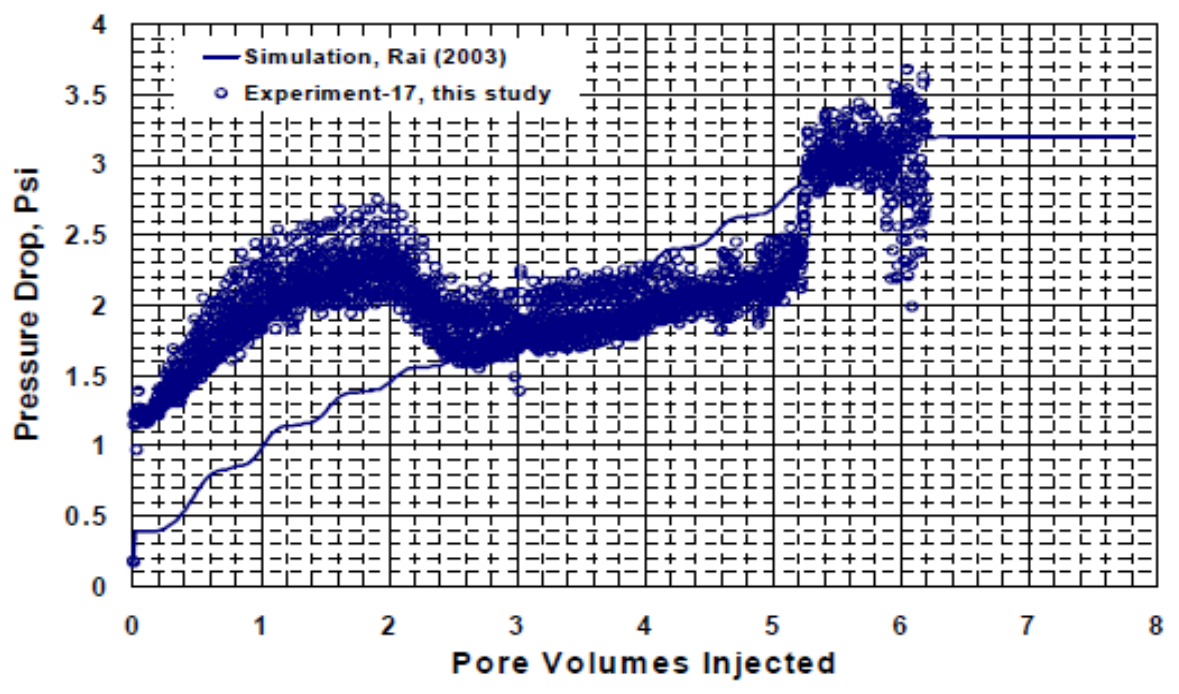

Figure 1: Pressure Drop vs. Pore Volumes Injected, Experiment No. 17, Al-Anazi et al., 2003

Core properties and operating conditions were unchanged and are shown in Table 2. Relative permeability data was generated using a Corey type function, and is shown in Figures 2 and 3. This was the main parameter tuned to obtain a history match.

Table 1: Core Model Properties from Al-Anazi et al., 2002 \& 2003

\begin{tabular}{|c|c|}
\hline \multicolumn{2}{|c|}{ Fluid A } \\
\hline Component & Mole Fraction \\
\hline C1 & 0.8 \\
\hline C4 & 0.15 \\
\hline C10 & 0.038 \\
\hline Initial Water Saturation, \% & 0.012 \\
\hline Reservoir Pressure, psi & 0 \\
\hline Reservoir Temperature, ${ }^{\circ} \mathrm{F}$ & 145 \\
\hline
\end{tabular}

Table 2: Core Model Properties from Al-Anazi et al., 2002 \& 2003

\begin{tabular}{|l|c|}
\hline \multicolumn{2}{|c|}{ Core Model Properties } \\
\hline Length, in. & 8 \\
\hline Diameter, in. & 1 \\
\hline Porosity, \% & 20 \\
\hline Pore Volume, cc & 20 \\
\hline Permeability, mD & 3.15 \\
\hline
\end{tabular}




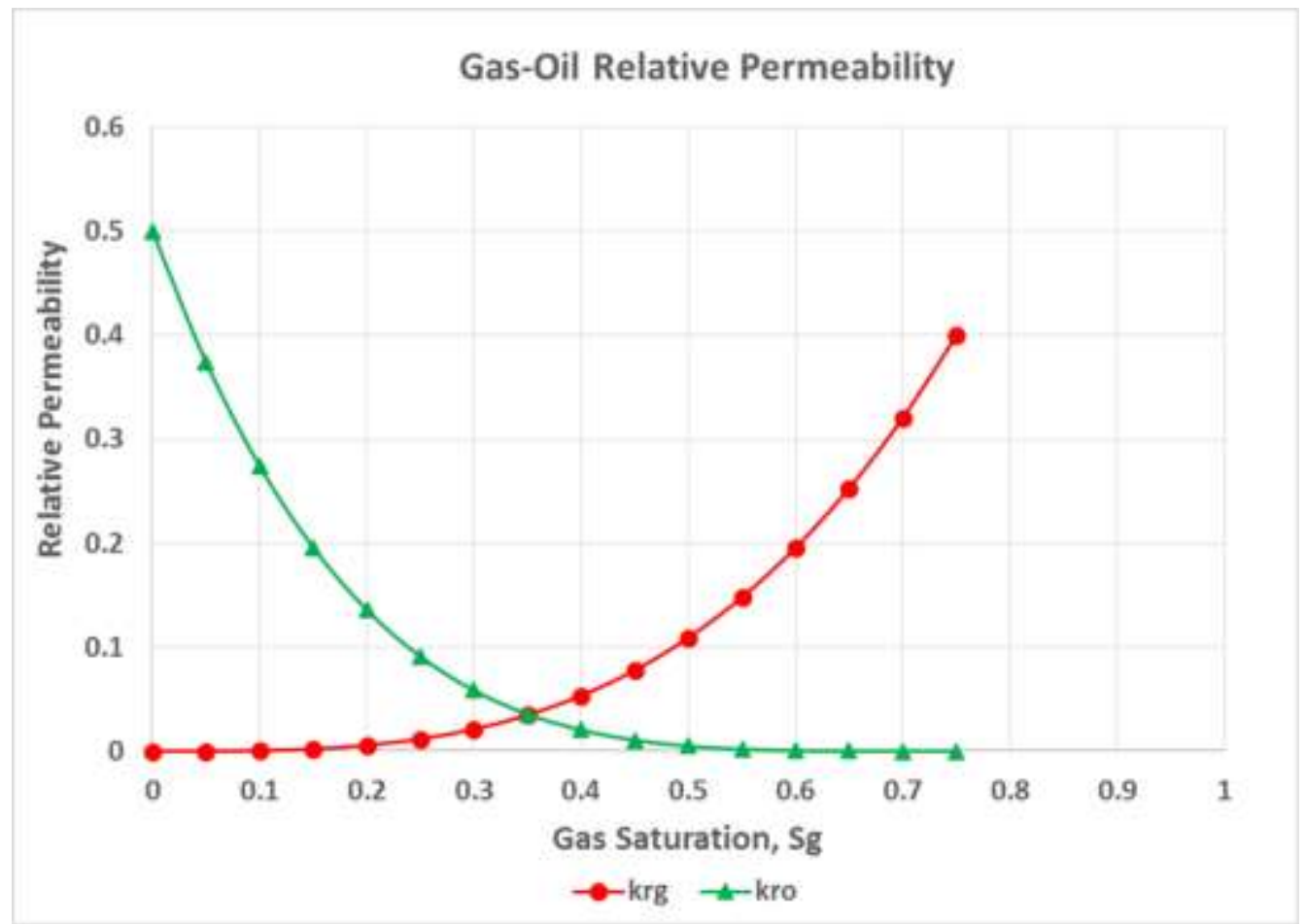

Figure 2: Gas-Oil Relative Permeability Data for Fluid A

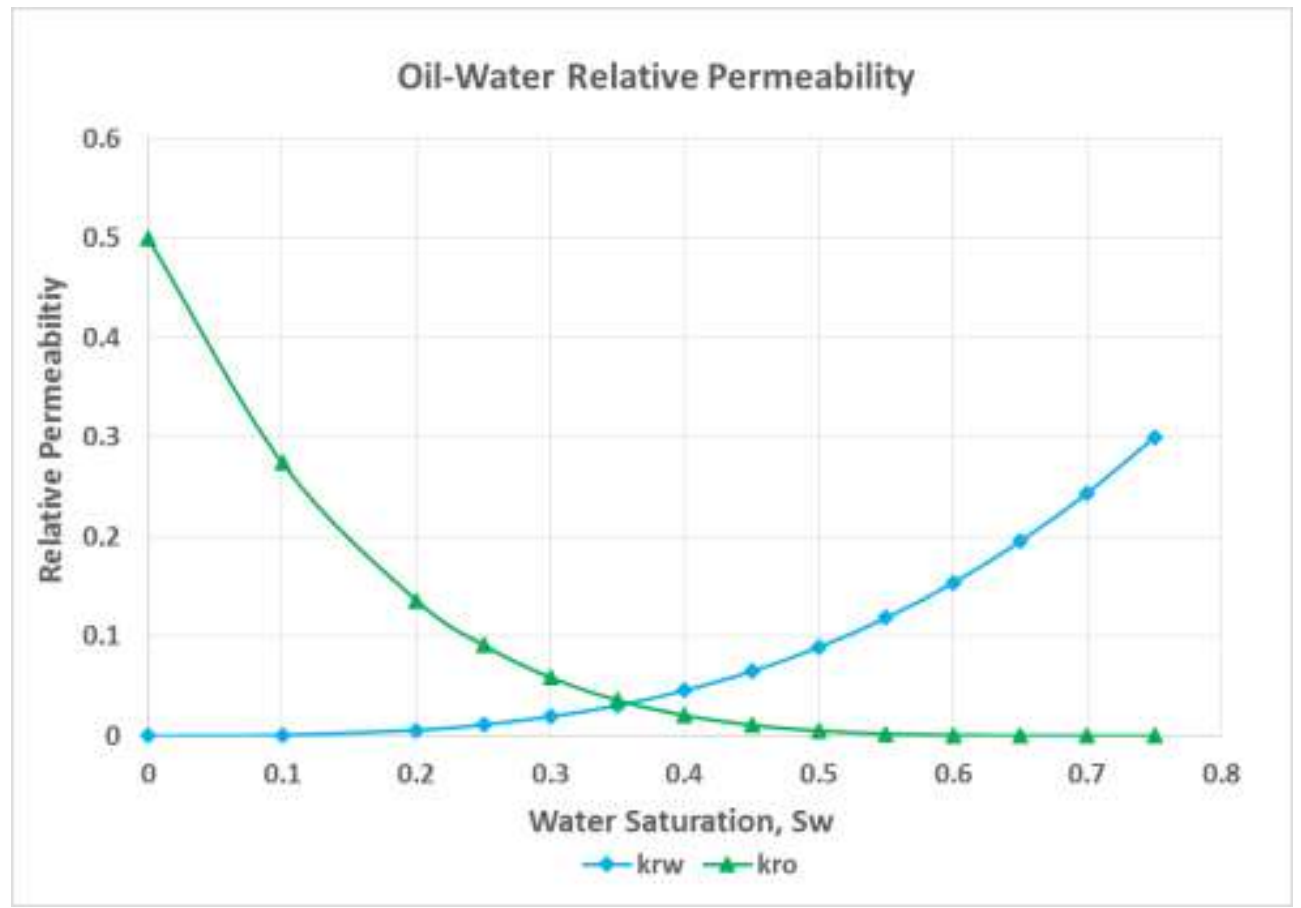

Figure 3: Oil-Water Relative Permeability Data for Fluid A

Tuned parameters of the relative permeability curve are given in Table 3: 


\begin{tabular}{|c|c|}
\hline $\boldsymbol{S}_{\mathrm{wr}}$ & 0 \\
\hline $\boldsymbol{S}_{\mathrm{or}}$ & 0.25 \\
\hline $\boldsymbol{S}_{\mathrm{gr}}$ & 0 \\
\hline $\boldsymbol{K}_{r 0^{\circ}}{ }^{\circ}$ & 0.5 \\
\hline $\boldsymbol{K}_{\mathrm{rg}}{ }^{\circ}$ & 0.4 \\
\hline $\boldsymbol{n}_{o}$ & 4.2 \\
\hline $\boldsymbol{n}_{g}$ & 3.2 \\
\hline $\boldsymbol{n}_{\mathrm{w}}$ & 3 \\
\hline $\boldsymbol{k}_{\mathrm{rw}}{ }^{\circ}$ & 0.3 \\
\hline
\end{tabular}

Table 3: Corey Function Parameters used to generate relative permeability data

In the Table 3, $S_{\mathrm{wr}}, \mathrm{S}_{\mathrm{gr}}$ and $\mathrm{S}_{\mathrm{or}}$ are the residual water, gas and oil phase saturations, $\mathrm{k}_{\mathrm{ro}}{ }^{\mathrm{o}}, \mathrm{k}_{\mathrm{rg}}{ }^{\mathrm{o}}, \mathrm{k}_{\mathrm{rw}}{ }^{\mathrm{o}}$ are the end point relative permeability for oil, gas and water phases, while $n_{o}, n_{g}$ and, $n_{w}$ are the Corey function exponents for the oil, gas and water phases, respectively.

The number of grids in the model were sensitized and varied in the I-direction to eliminate errors caused by numerical dispersion. The final grid model is a 1-D 24X1X1 model depicting an 8 "X1" core. The producer is at the block $(1,1,1)$ and the flowing bottom-hole pressure was 1200 psi. The injector is at the block $(24,1,1)$ and the injection rate is $2 \mathrm{cc} / \mathrm{hr}$ at the injection pressure of 3000 psi.

Our simulation result was overlaid over the original plot to obtain a history match. This is shown in the Figure 4. The red data points are the regenerated simulation results. Al-Anazi's work obtained a steady state pressure drop after injecting 5.5 PV of single phase gas. Rai et al. (2003) simulated this data and obtained a match at 6.2 PV of injected gas and we obtained a history match at 5.5 PV. The hump in pressure drop seen in the experimental results at low injected pore volume was exclusive to this experiment in Al-Anazi's work and this trend was not seen for other experiments. Neither Rai's work nor our work was able to capture this detail. 


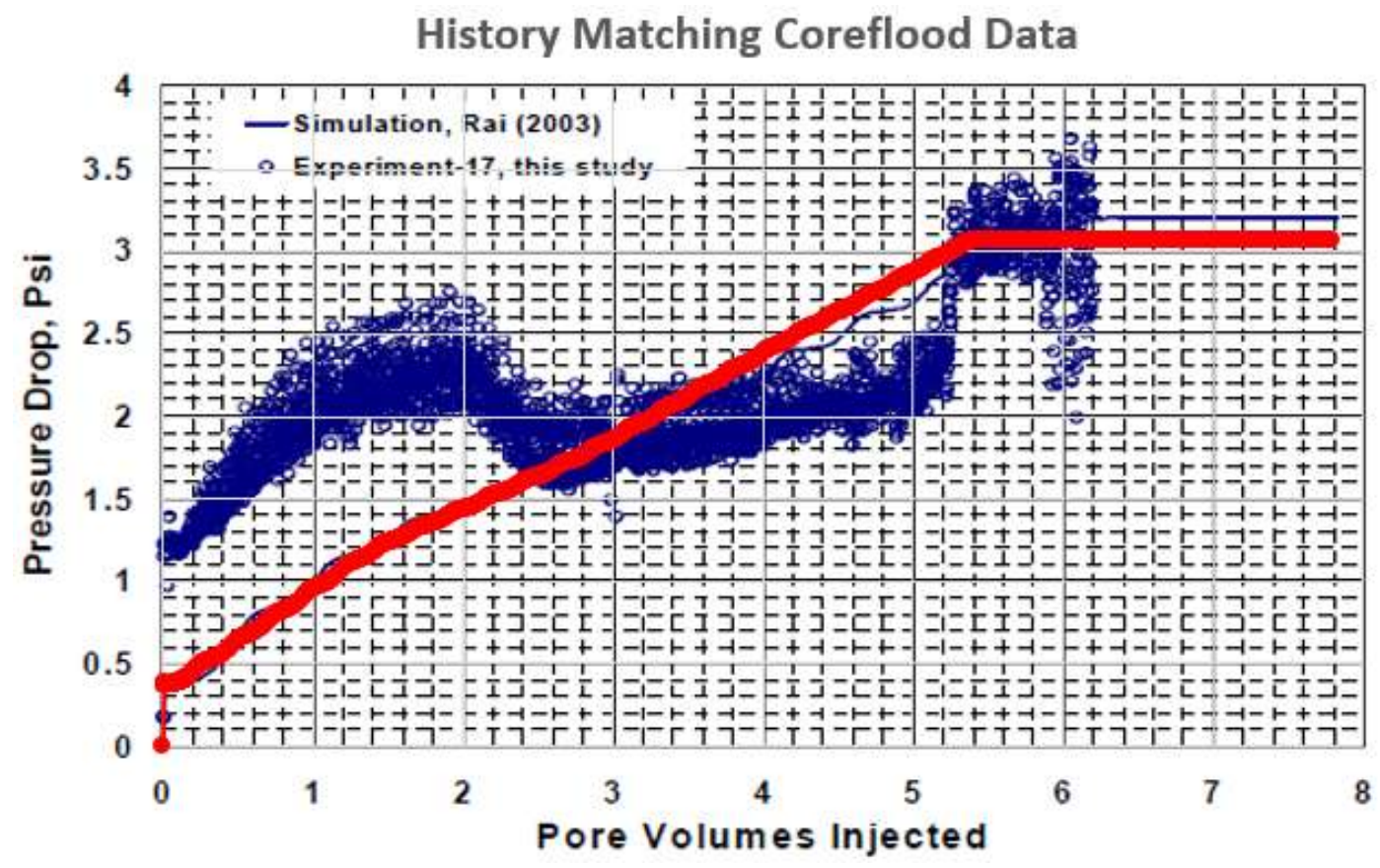

Figure 4: History matching published coreflood data, Al-Anazi et al., 2003

\subsection{Reservoir Fluid Model}

In order to correctly model interaction of the solvent phase with the hydrocarbons, phase behavior properties of binary interaction coefficients (BIC) between the solvent and reservoir fluid components need to be modeled (Bang et al, 2010; Ganjdanesh et al., 2015). This takes into account the polar interaction of the alcohol solvent with the hydrocarbon components. Bang et al. (2010) have done extensive work on generating a linear function of binary interaction coefficients and volume shift parameters with temperature for use with the Peng Robinson Equation of State (PREOS, 1978). This data is available for Fluid A, but only for methanol not isopropanol. Thus, Fluid A was used when comparing results between all injection fluids except isopropanol.

A second fluid mixture termed as Fluid B in this paper was also tuned by Bang et al., 2010 for interactions with both methanol and isopropanol solvents. Fluid A and Fluid B differ only in the mole fraction of the components and consist of the same four synthetic components - methane, butane, heptane and decane. This second model with Fluid B also has initial water saturation of $25 \%$ and the relative permeability data had to be adjusted to account for a residual water saturation of $25 \%$. 


\begin{tabular}{|c|c|}
\hline \multicolumn{2}{|c|}{ Fluid B } \\
\hline Component & Mole Fraction \\
\hline C1 & 0.81 \\
\hline C4 & 0.05 \\
\hline C7 & 0.06 \\
\hline C10 & 0.08 \\
\hline Initial Water Saturation, $\%$ & 25 \\
\hline Reservoir Pressure, $\mathrm{psi}$ & 4000 \\
\hline Reservoir Temperature, ${ }^{\circ} \mathrm{F}$ & 300 \\
\hline
\end{tabular}

Table 4: Composition of mixture for Fluid B, Bang et al., 2010

The phase behavior work by Bang et al. was regenerated using CMG Winprop for use in our GEM simulation models. The initial reservoir pressure and temperature of the core were same as for Al-Anazi's work for Fluid A, but had to be changed for Fluid B depending on the phase envelope (Figure 5) and the dew point pressure of the gas-condensate mixture. These details of Fluid B are given in Table 4.

As presented in the previous section, we used Fluid A to build a base model as the core flood data were available. Then we used Fluid B to further run a sensitivity on the composition of the reservoir fluid, compared with Fluid A. In the model using Fluid B, we also include water saturation which is closer to a real reservoir condition. Hydrocarbon recovery and mechanisms were investigated.

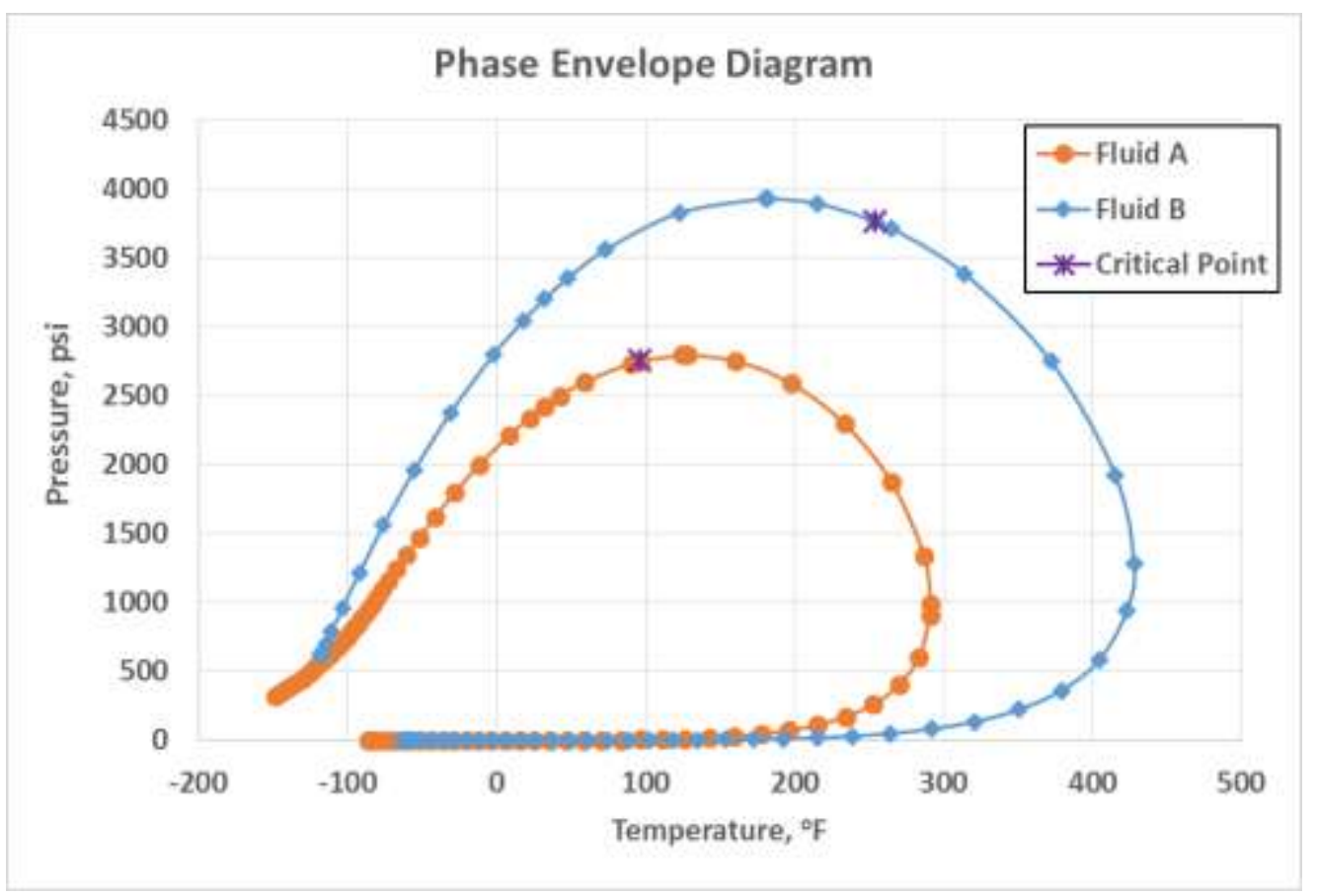

Figure 5: Phase Behavior Diagram for Fluid A \& Fluid B, Al-Anazi et al., 2002 and Bang et al., 2010 
Figure 6 shows a higher maximum liquid dropout of $25 \%$ for Fluid B as compared to $18 \%$ for Fluid A. This is owing to a richer composition of heptane and decane for the former fluid. At the flowing bottom hole pressure of $1200 \mathrm{psi}$, both fluids have about the same liquid dropout of $7.5 \%$ as suggested by phase behavior. Fluid A has a dew point pressure of 2795 psi and Fluid B has a dew point pressure of 3500 psi.

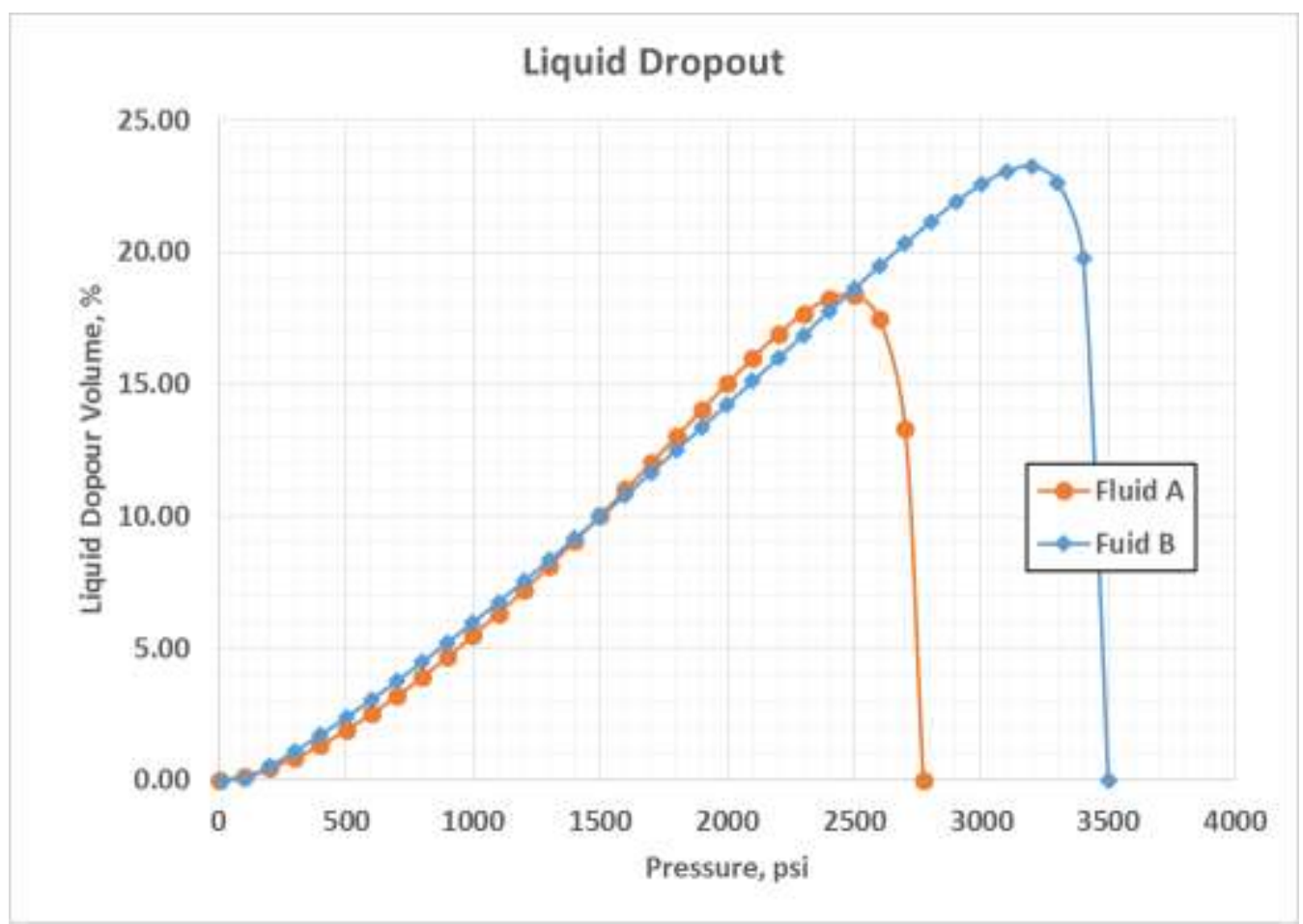

Figure 6: Liquid Dropout for Fluid A \& Fluid B, Al-Anazi et al., 2002 and Bang et al., 2010

\subsection{Choosing the Injection Fluids}

Methanol is already established as a successful application in removing condensate and water blocks from the near well bore regions in both low and high permeability cores using a flooding mechanism (Du et al, 2000; Walker et al, 2000; and Al-Anazi, 2003) and one cycle of huff-npuff treatment in the Hatter's Pond Field (Al-Anazi et al., 2003) where re-formation of a condensate bank was delayed. Alternatively, isopropanol has only been studied in phase behavior experiments with gas-condensate fluids (Bang et al., 2010). A combination of isopropanol and propylene glycol was also screened to be the best delivery system for fluorinated surfactants for condensate blockage treatment (Bang et al., 2010). The purpose of the solvent was to remove resident fluids around the wellbore such as brine and condensate and to enable a clean adsorption site for the surfactants. Isopropanol (IPA) has been studied for displacement of synthetic oil and water from porous media (Gatlin, 1959). Gatlin's flooding experiments showed that isopropanol was completely miscible with oil and water forming a single phase but required a certain critical concentration to achieve this. For IPA, $13.5 \%$ of the entire pore volume was required to completely displace all residual oil. Based on this research IPA was included for comparing recovery efficiencies from gas-condensate cores. 
Similar to the above approach, methane has already been established as an efficient gas for recovering residual condensate (Abel, 1970). Meng et al., 2015 successfully applied this concept to huff-n-puff injection of methane for extremely low permeability shale cores. A full scale reservoir simulation and optimization of this method for shale gas condensate cores has also been recently covered (Meng et al., 2016). However, very limited work has been documented on ethane injection for recovering condensate from conventional or unconventional reservoirs. According to an article in the Oilfield Review (Harris et al., 2005), a combination solvent of ethane and propane followed by dry gas was injected into single pilot wells in the Vutkyl Field for remediating near wellbore condensate blockage. Over a period of 6 months to 1.5 years, the productivity of the four tested wells increased in the range of 20-40\%. Also, some experimental work was conducted for comparing ethane and $\mathrm{CO} 2$ as EOR injectants for viscous oils in the West Sak field (DeRuiter 1994). Their work demonstrated the superiority of ethane in viscosity reduction and achieved miscibility. Ethane is recently gaining attention as an EOR injection gas for shale reservoirs because of its low cost (McGuire et al., 2016). These low costs and high volumes of ethane availability are attributed to horizontal well and hydraulic fracturing development of shale reservoirs that revolutionized production from the oil and gas industry.

A simple phase behavior study of Fluid A, on addition of four gas components, are summarized in Figure 7. 15\% of each gas was added individually. Results show that methane reduces the maximum liquid drop out of the original fluid the most, as shown by the reduction in liquid drop out from $18 \%$ to $11 \%$, while it does not change the dew point pressure. Propane significantly reduced dew point pressure of the fluid mixture. However, it also increased the liquid dropout tremendously. $\mathrm{CO}_{2}$ and ethane showed similar liquid dropout, however, the dew point reduction for ethane was relatively higher. Additionally, application of $\mathrm{CO}_{2}$ is not cheap with added costs of corrosion inhibition. Thus, ethane was chosen for comparison with other injection fluids for this work.

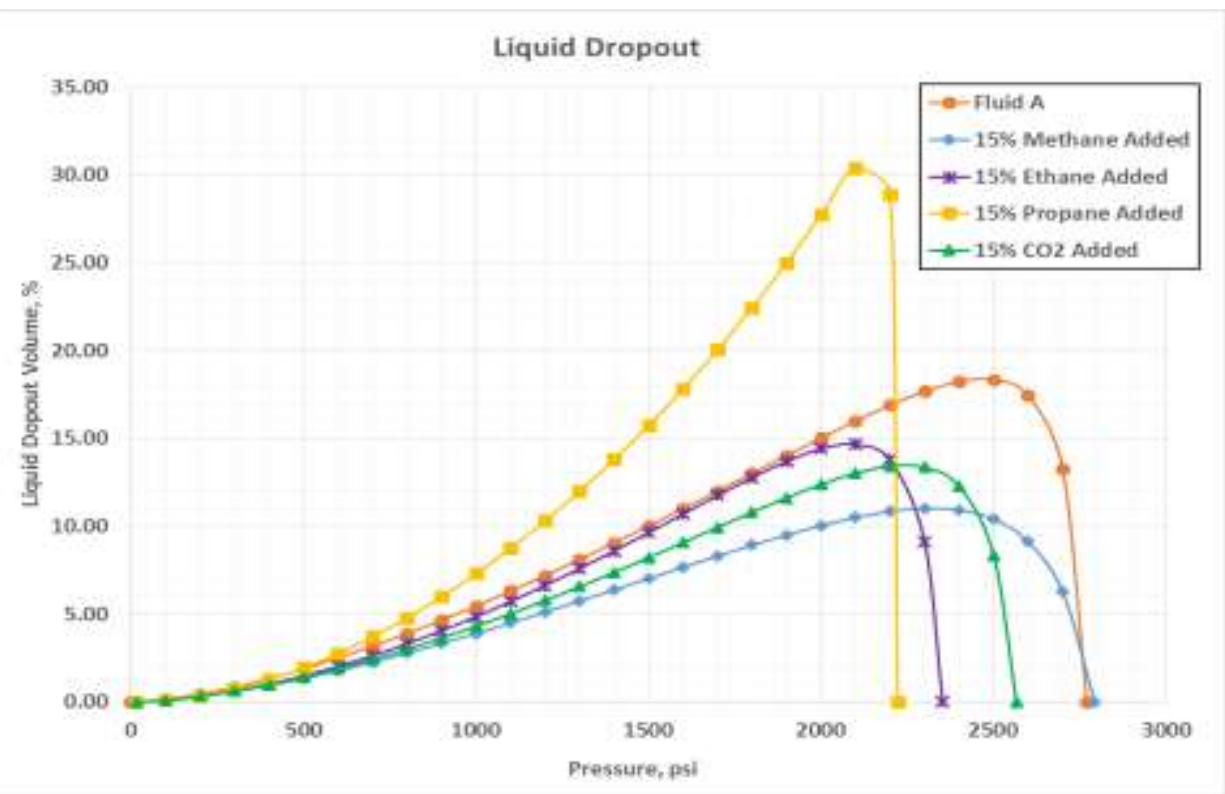

Figure 7: Change in Liquid Dropout and Dewpoint of Pressure of Fluid A after 15 mole percent addition of gases 


\subsection{Recovery Factors}

It is important that the injected fluid be removed from the produced phase to accurately calculate recovery of total hydrocarbon in place. Recovery factors were calculated as expressed below:

$\frac{\text { (Cumulative hydrocarbons produced after primary depletion-Cumulative injection fluid produced) }}{\text { (Original hydrocrbons in place at end of primary depletion) }} \frac{B O E}{B O E}$

All volumes used for calculations are at the standard condition of $14.7 \mathrm{psi}$ and $60^{\circ} \mathrm{F}$. BOE stands for barrel of oil equivalent. For ethane and solvents, the calculations were split into two parts: oil phase and gas phase.

Volume recovery in the oil phase:

$$
\sum_{i}^{n} \frac{N_{i} * M W_{i}}{\rho_{i}}-\text { Cumulative oil recovery from primary depletion }
$$

In the above equation, $\mathrm{i}$ to $\mathrm{n}$ are the total components from methane to decane. $\mathrm{N}$ is the gmole recovered for each component, $\mathrm{MW}$ is the molecular weight of the component in gms and $\rho$ is the density of the component in gms/cc. All volumes were converted to bbls using a conversion factor:

$$
1 c c=6.29 E-6 b b l s
$$

Volume recovery in the gas phase:

$$
\sum_{i}^{n} \varphi_{i} * V_{t}-\text { Cumulative gas recovery from primary depletion }
$$

where,

$$
\begin{gathered}
\varphi_{i}=X_{i} \\
X_{i}=\frac{N_{i}}{N_{t}}
\end{gathered}
$$

In the above equation, $\mathrm{N}_{\mathrm{t}}$ is the total number of gmoles of recovered gas including the injected fluid, $\mathrm{i}$ to $\mathrm{n}$ are the total components from methane to decane, $X_{\mathrm{i}}$ is the mole fraction of the individual component, $\varphi_{\mathrm{i}}$ is the volume fraction of each component and $\mathrm{V}_{\mathrm{t}}$ is the cumulative gas produced. At the standard conditions, and under the ideal gas law assumption, mole fraction and volume fraction of a gas component are equal. Thus, the total volume of hydrocarbons recovered in the gas phase can be calculated. This volume is calculated in scf and is converted to barrel of oil equivalent (BOE) using the following conversion:

$$
1 B O E=5800 s c f
$$


Volumes from the oil and gas phases were added after the above calculations to obtain total BOE of hydrocarbons recovered. Using the described method, we have recovery volumes which are corrected for the injected fluid volume that flows back in the produced stream.

Hydrocarbon recovery volumes for methane injection were calculated differently. This is because it is complex to differentiate between injected methane and the recovered methane in the produced stream. A simple material balance was used for the same:

Cumulative injected volume of methane $(I)=$ Additional methane volume in place in core (A) + Volume of injected methane in the produced stream (B)

Rearranging the above equation:

$$
B=I-A
$$

$A=$ Cumulative methane volume in place in core - Original methane volume in place after primary depletion

Cumulative hydrocarbon recovery = Cumulative volume of hydrocarbon produced after primary depletion $-B$

Total hydrocarbons in place after primary depletion, BOE:

$$
\text { Total oil in place, bbls }+\frac{\text { Total gas in place, } s c f}{5800}
$$

Note, that all volumes are in barrel of oil equivalent (BOE) and recovery factors for all injection fluids can be compared equally after the above calculations.

\section{Results and Analysis}

All models were run with a constant bottom-hole pressure of 1200 psi. Producer well is located at $(1,1,1)$ and the injector well is located at $(24,1,1)$. The injection pressure for each case was constrained at or close to initial reservoir pressure, for the near well bore region. This ensures that the maximum possible fluid volume could be injected into core. To investigate the application of these EOR methods to shale gas-condensate reservoirs, the permeability of the core model was changed from $3.15 \mathrm{mD}$ to 315 nano-darcy (nD). Porosity of the model was changed from $20 \%$ to $6 \%$.

\subsection{Case 1: Fluid A - Huff-n-Puff Comparison of Methane, Ethane and Methanol Injection}

During the huff period, the injection pressure is $2850 \mathrm{psi}$, which is above the dew point pressure. When the pressure at the block $(4,1,1)$ approximately reaches the injection pressure of $2850 \mathrm{psi}$, operation was switched to the puff period. During the puff period, the bottom-hole flowing pressure is 1200 psi. When the pressure at the block $(4,1,1)$ approximately reaches 1200 psi, operation was switched to the huff period. Such process is repeated. 
Huff-n-puff of both gases and solvent were run for 130 days so we are able to compare them for the same time period. Isopropanol was not included because it was not used in the coreflood experiment. Recovery factors were compared on three basis - operation time, pore volume of injected fluid and cost of the injection material. Pore volumes of the injected gases are converted to BOE volumes so they can be compared to solvent injection. All pore volume calculations are at surface conditions to enable a cost comparison.

Cost of the injection material are summarized in Table 5:

\begin{tabular}{|c|c|c|c|}
\hline Injection Fluid & Cost & Unit & Source \\
\hline Methane & 3.17 & $\$ / M s c f$ & ElA, spot price \\
\hline Methanol & 0.88 & $\$ /$ gal. & Methanex, spot price \\
\hline Ethane & 4.15 & $\$ / M s c f$ & End of January (McGuire et al., 2016) \\
\hline
\end{tabular}

Table 5: Cost of material for the injection fluids

Figures 8 shows that ethane delivers the highest recovery of the cumulative BOE volume based on the hydrocarbons in place at the end of primary depletion. It has a recovery of 54\% followed by methanol with a recovery of $25.1 \%$ and then methane with a recovery of $18.4 \%$. Ethane also proves to be the most efficient gas because it recovers a much higher volume percent of hydrocarbon in place for the same volume of injected fluid (Figure 9) and the same cost of material (Figure 10) when compared to methane and methanol. 


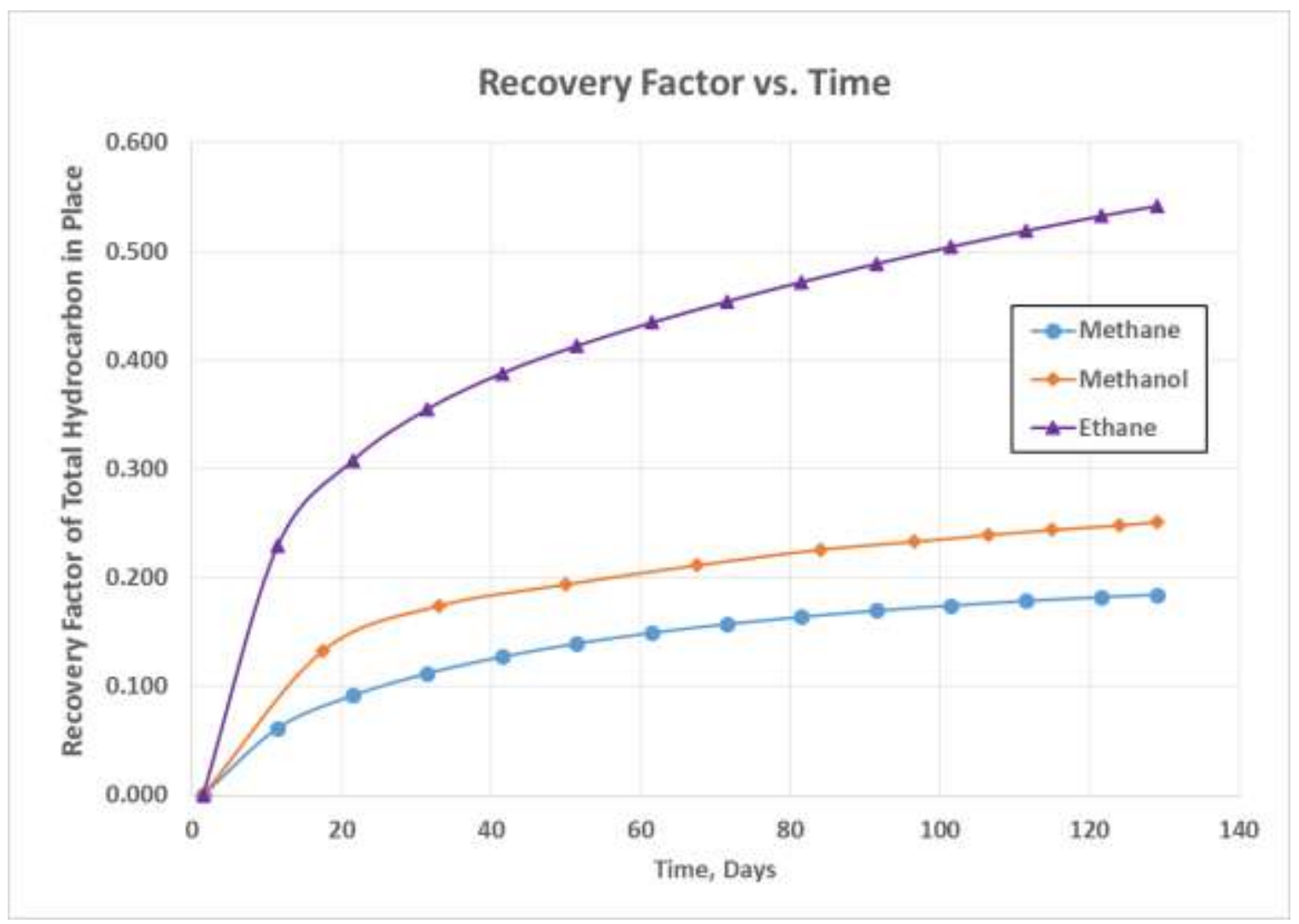

Figure 8: Case 1 - Recovery Factor vs. Huff-n-Puff Time 


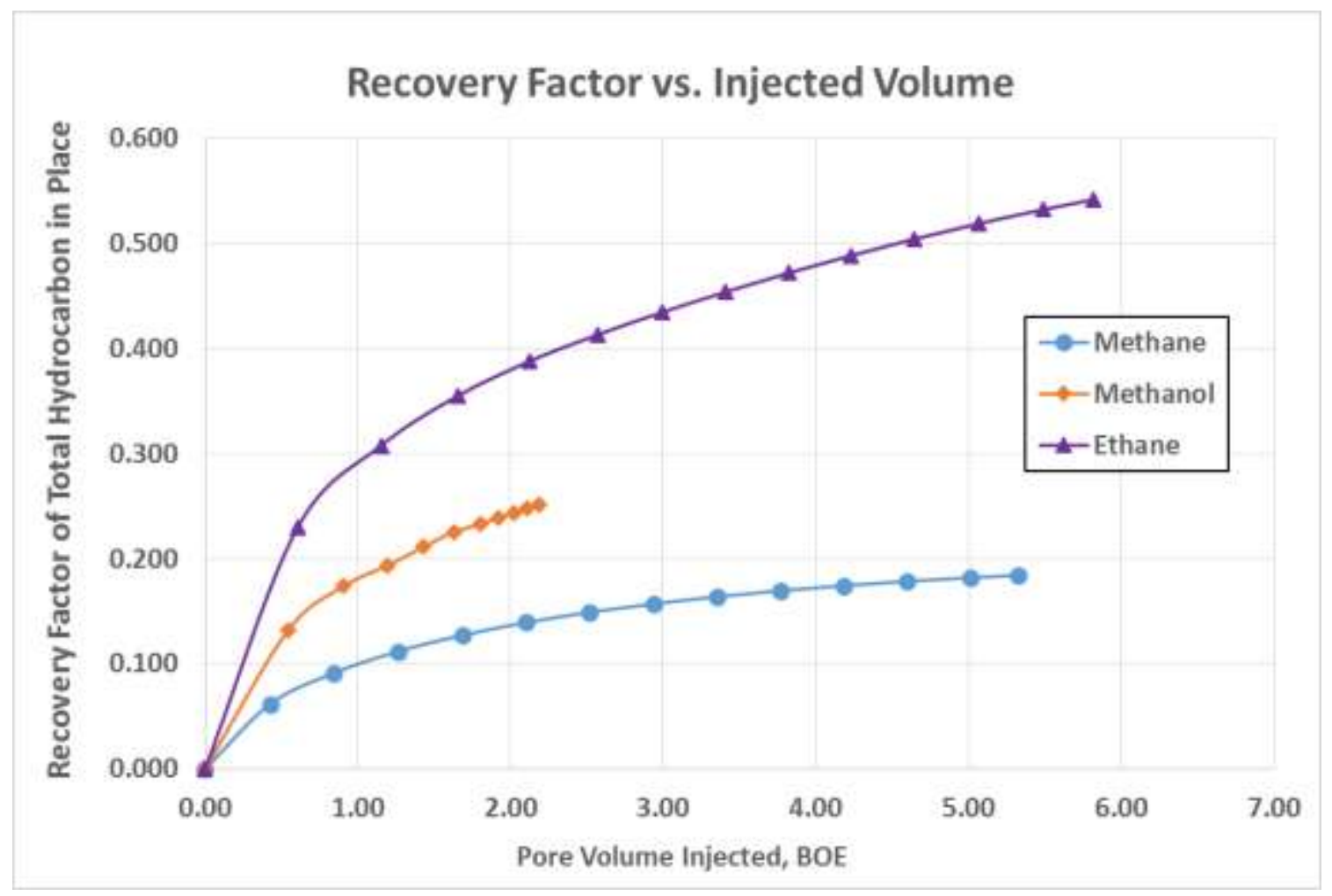

Figure 9: Case 1 - Recovery Factor vs. Injected Pore Volume

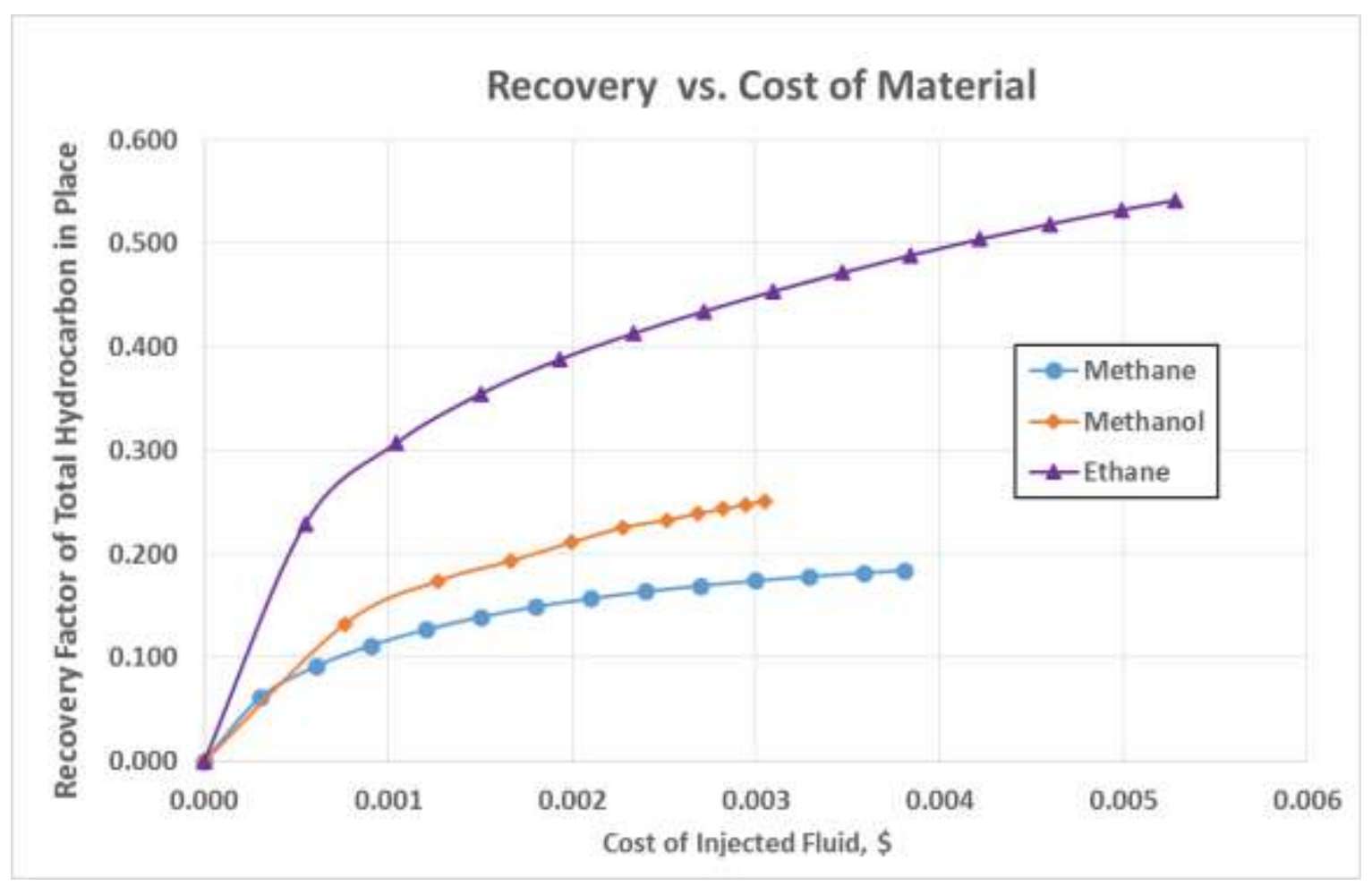

Figure 10: Case 1 - Recovery Factor vs Total Cost of Injected Material 
However, these results are inconclusive without looking at the individual component recovery of the original hydrocarbon fluid. The cumulative recovery for each component is calculated in terms of BOE as a fraction of the original BOE volume of the component in place at the end of primary depletion. Figure 11 shows that methanol has good recoveries for methane and butane, but not as much for heptane and decane. Methane on the other hand has a $0.2 \%$ recovery for methane but in comparison to methanol recovers a higher volume of butane, heptane and decane. The large difference in methane component recoveries is what causes the total $\mathrm{BOE}$ recoveries to be higher for methanol as compared to methane. This result is really important because the condensate dropout in the core is mostly composed of $\mathrm{C} 4, \mathrm{C} 7$ and $\mathrm{C} 10$ components. Therefore, methane is more effective than the methanol to mitigate condensate dropout.

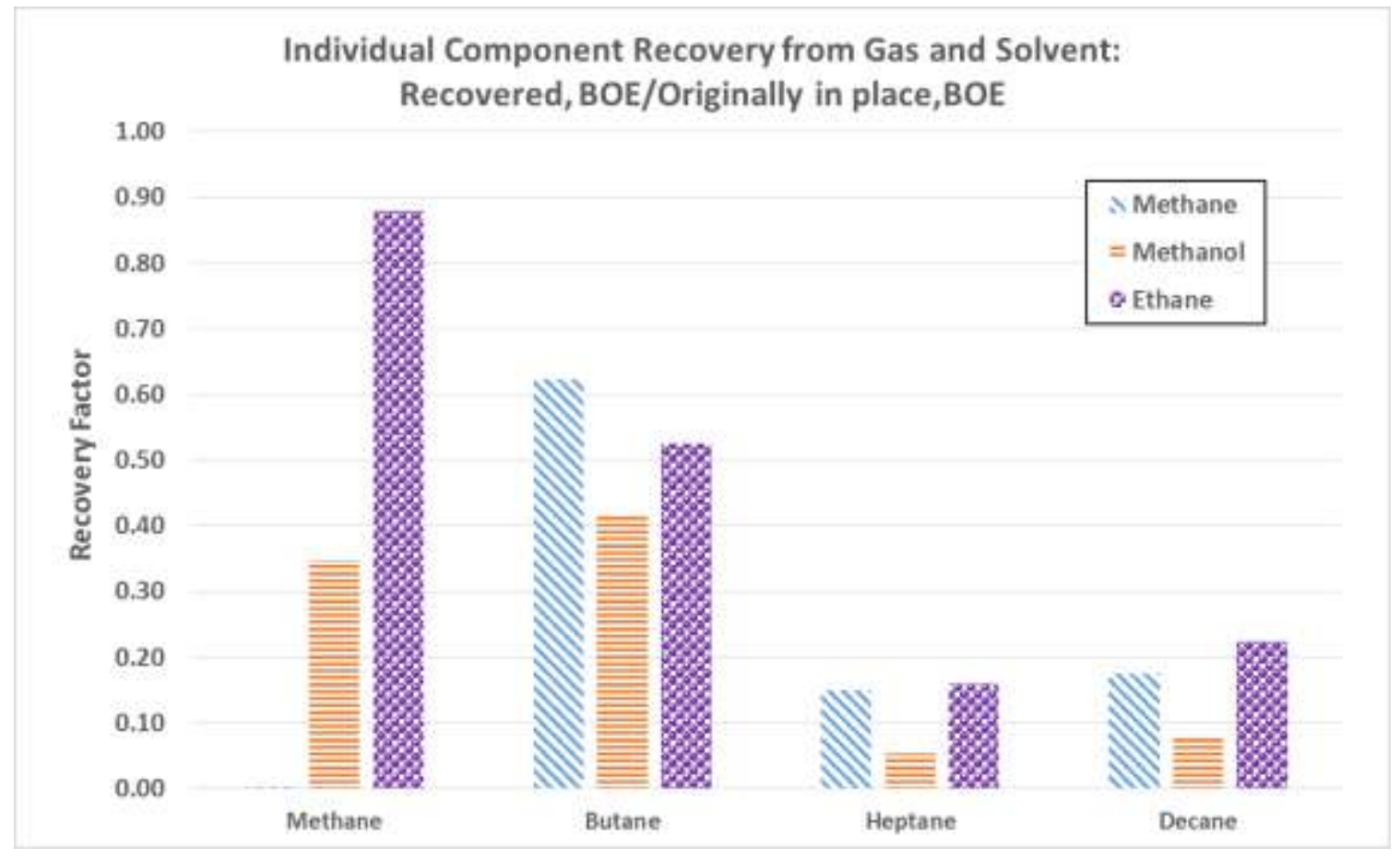

Figure 11: Case 1- Individual component recovery from each injection fluid

As the component gets heavier, ethane becomes more effective as compared to methane. Its performance is lower than methane injection for recovering butane, comparable for recovery of heptane, and much better in recovering decane. Additionally, ethane recovers high volumes of methane, specifically $88 \%$ of the in place BOE volume. Figure 12 summarizes the recovery of heavy component in place on the BOE basis and without considering methane. The results indicate ethane and methane to be comparable with $\sim 30 \%$ recovery followed by methanol with $18 \%$ recovery. 


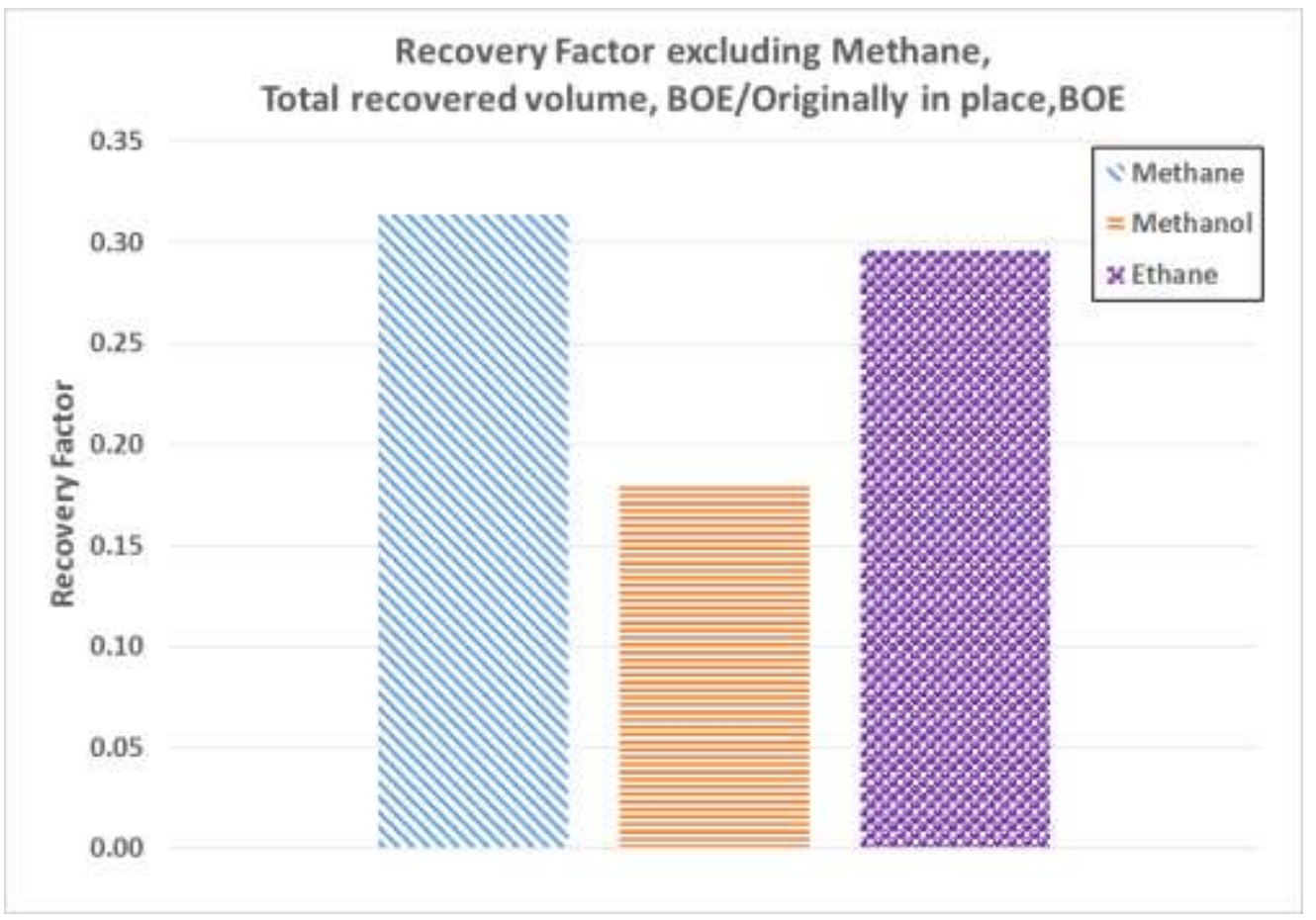

Figure 12: Case 1 - Intermediate and heavy liquids recovery from each injection fluid

Methanol will be a good solvent for leaner condensate fluids while methane and ethane injection will have higher recoveries for richer condensate fluids. However, the biggest advantage of using ethane over methane and methanol, as seen in Figures 8-19, is higher total hydrocarbon recovery factors for the same time of huff-n-puff time.

\subsection{Case 2: Fluid B - Huff-n-Puff Comparison of Gases and Solvents}

Huff-n-puff of both gases and solvent were run for 80 days. Injection pressure during huff period was changed to 4000 psi, higher than the dew point pressure of Fluid B and same as the reservoir pressure. The flowing bottom-hole pressure during puff period is maintained at 1200 psi. The huff-n-puff procedure is same as for the previous case. Results in this section (Figures 13-15) corroborate our previous conclusion. With the change in fluid type from $A$ to $B$, we changed to a richer fluid with a higher composition of heptane and decane. Butane content is very low for this fluid. We observe that methane now performs much better than solvents, isopropanol and methanol, with recoveries of $47.8 \%, 21.2 \%$ and $19 \%$ respectively.

Ethane recovery surpasses all of the other injection materials, with a $73 \%$ recovery of the total fluids in place. At this point, ethane has reached its maximum possible recovery factor and we also see methane recoveries beginning to stabilize. However, the two solvents are still showing a slow but steady increase in recovery factor. 


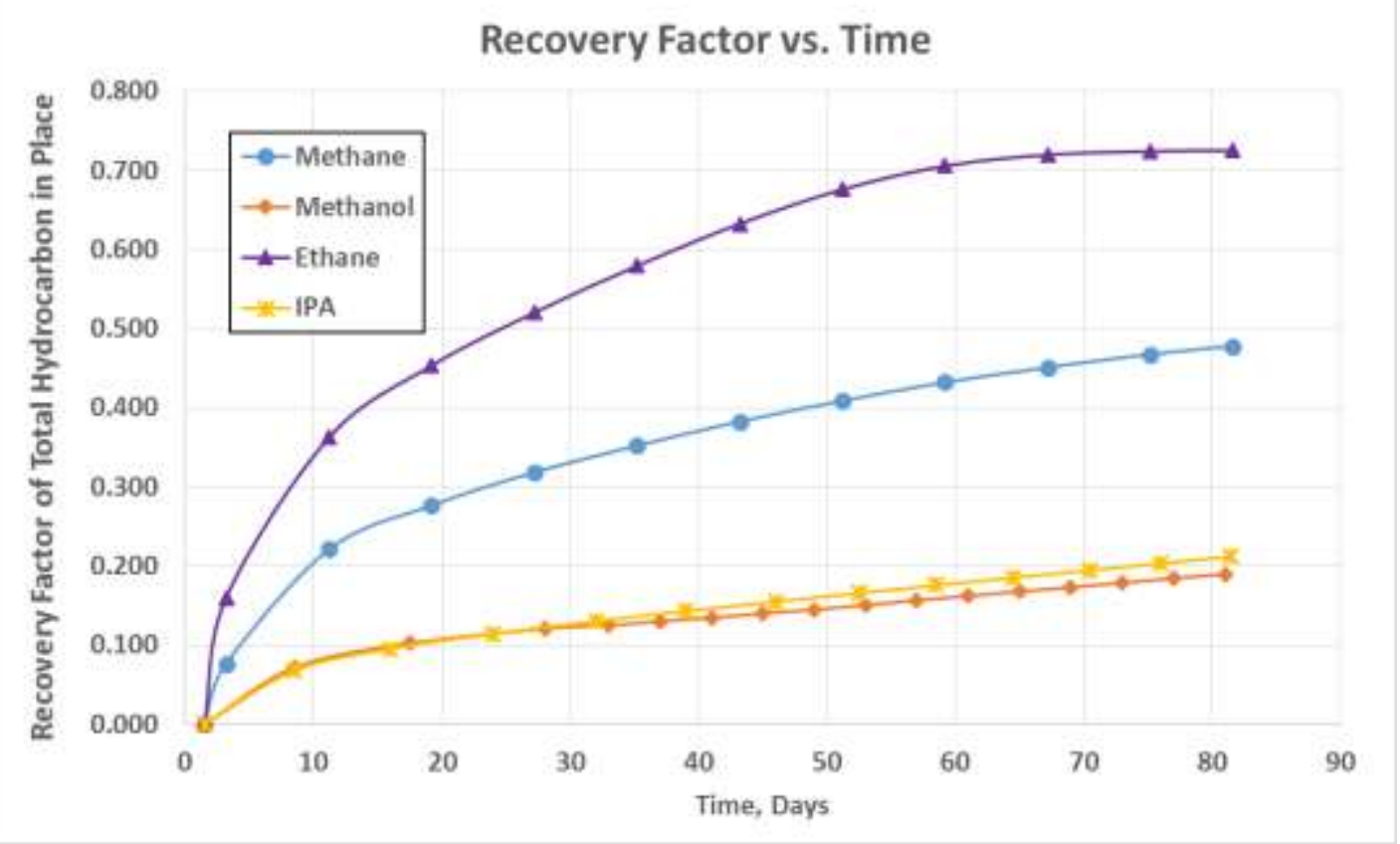

Figure 13: Case 2 - Recovery Factor vs. Huff-n-Puff Time

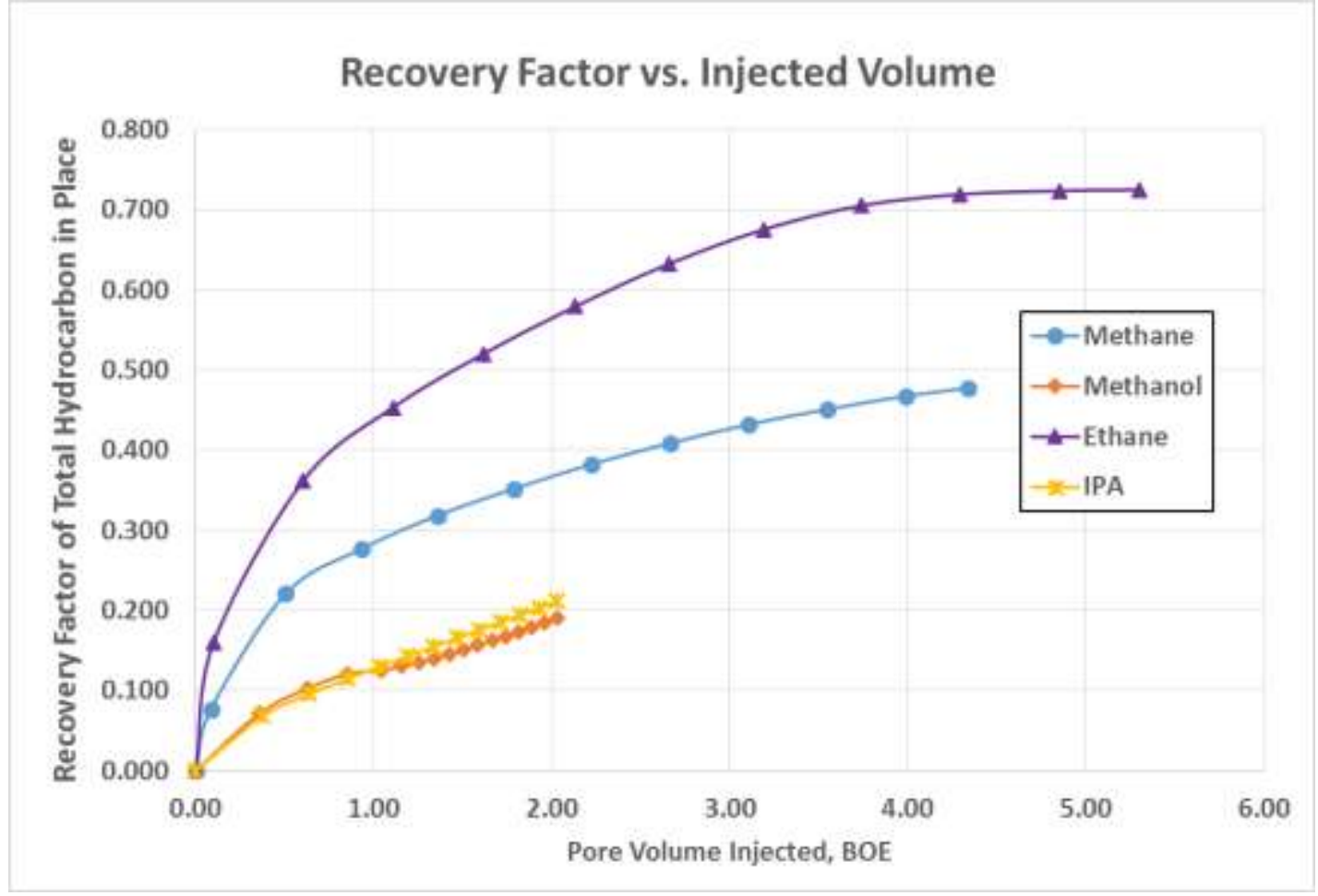

Figure 14: Case 2 - Recovery Factor vs. Pore Volume Injected 


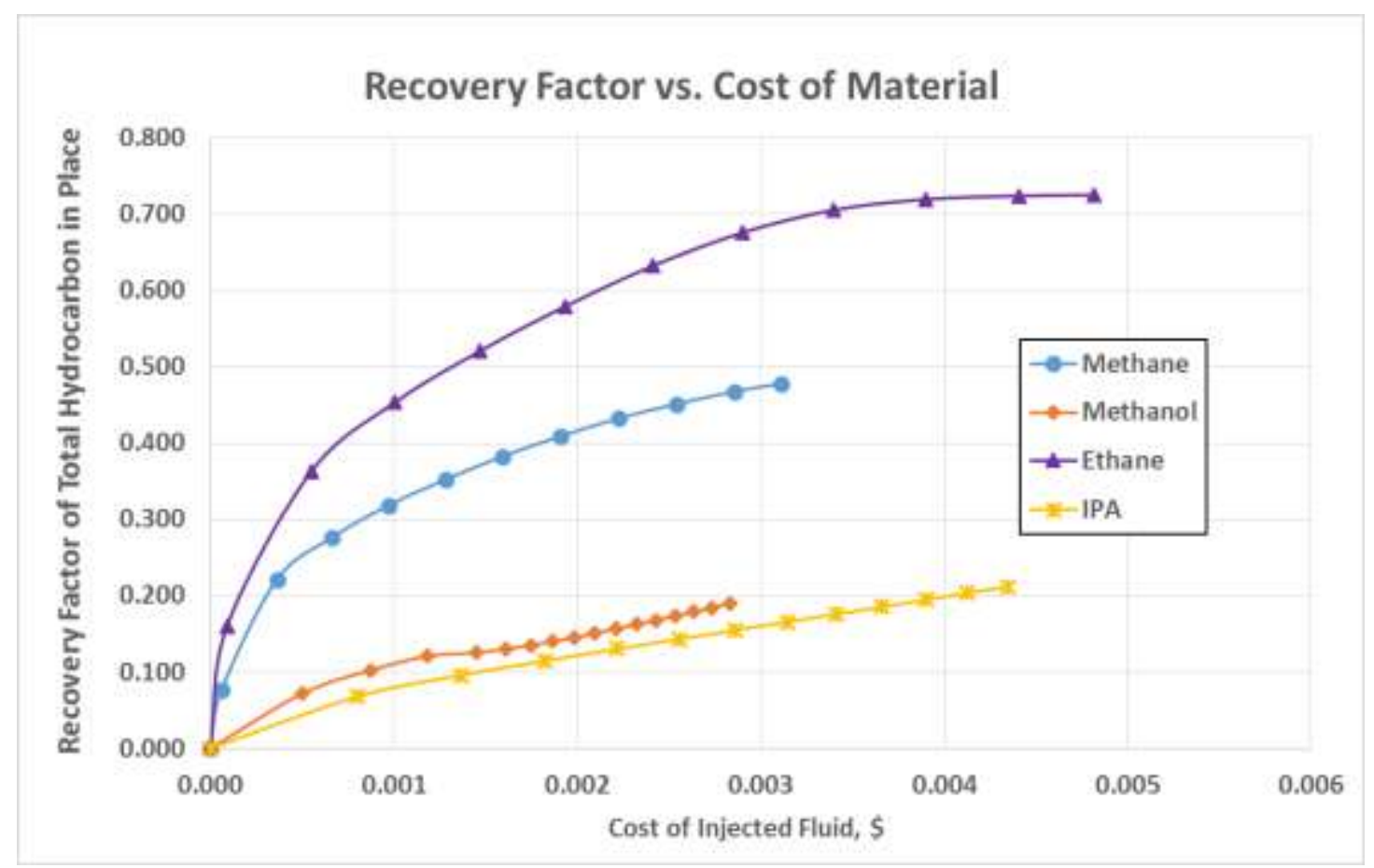

Figure 15: Case 2 - Recovery Factor vs. Total Cost of Injected Material

On a pore volume injected and cost basis, the gases still perform better than the solvents. The performances of methanol and IPA are almost comparable on the time or the injected BOE pore volume basis. Spot price for IPA was not available. However, it is known to be more expensive than methanol and an estimated cost of \$1.35/gallon was used for IPA when comparing costs. This is the best case scenario for the IPA cost. However, even this cost will not justify choosing IPA over methanol with a cost of \$0.88/gallon.

Component recovery graphs (Figures 16 and 17) paint a similar picture as for Fluid A. Methane and ethane recoveries are far better than the solvents when heavier components are higher in percentage in the initial reservoir fluid. While methane and ethane have similar recoveries for heavy components, ethane recovers $97.8 \%$ or almost all of the methane in place.

Between the two solvents, IPA does a better job of recovering the intermediate and heavy components as compared to methanol. However, costs may not justify this marginal difference in recoveries. 


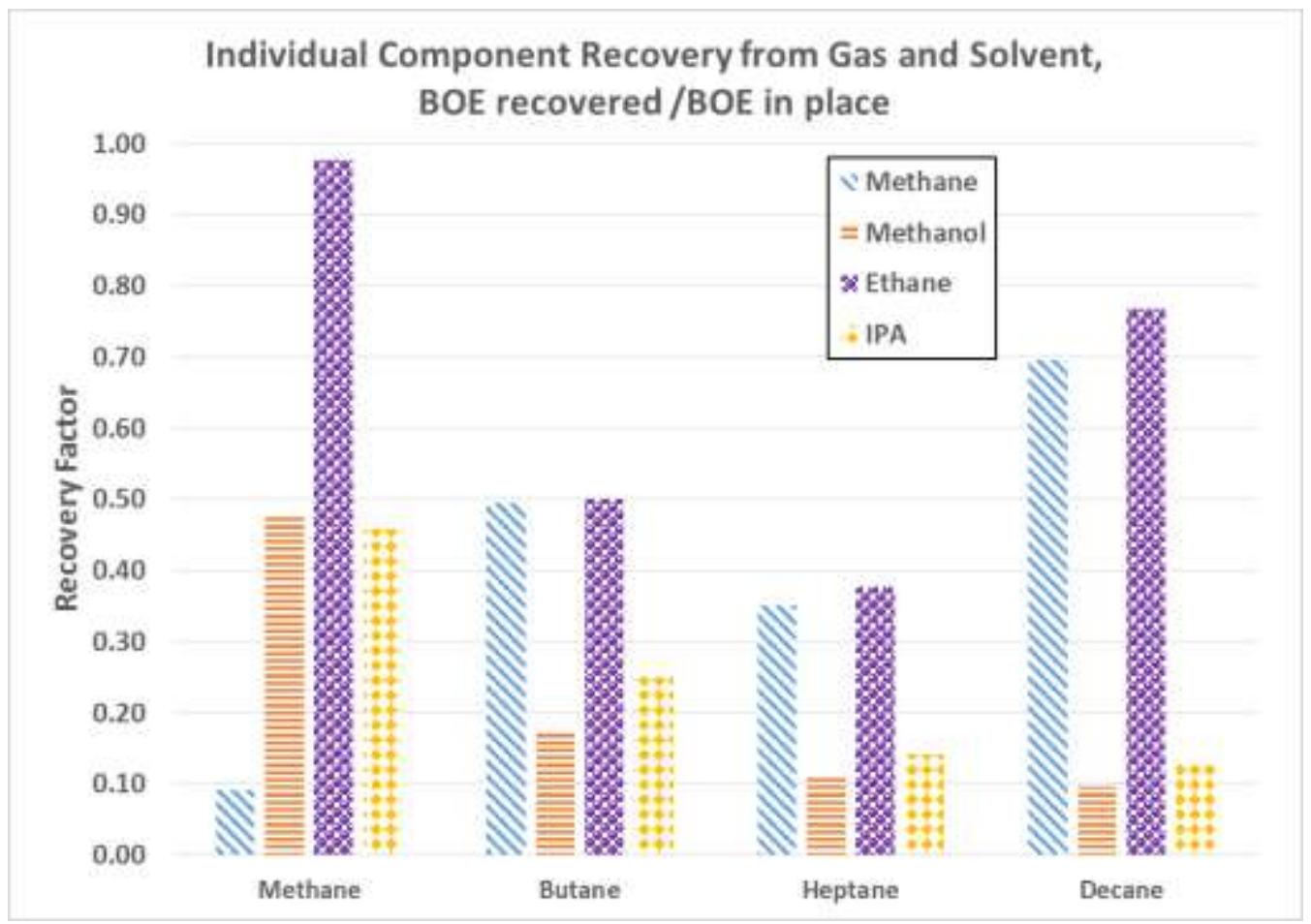

Figure 16: Case 2 - Individual component recovery from each injection fluid

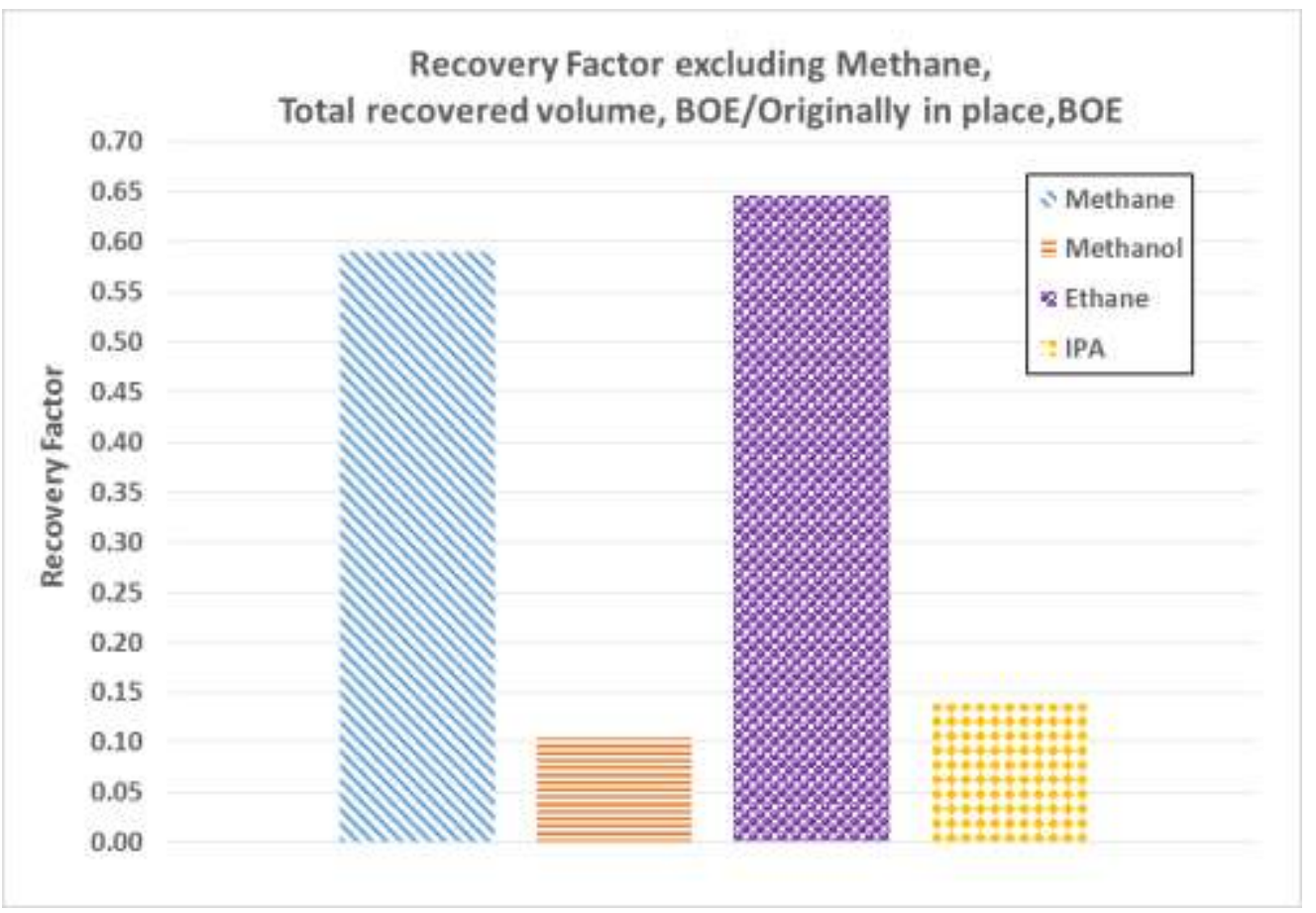

Figure 17: Case 2 - Intermediate and heavy liquids recovery from each injection fluid 


\subsection{Mechanisms}

Results from Fluid A are used to understand the differences in mechanism between gases and a solvent (methanol).

\subsubsection{Ethane and Methane}

We first compare the difference in recovery mechanisms of methane and ethane. Figure 18, for ethane, shows the oil viscosity, oil saturation and pressure in the $10^{\text {th }}$ block for the first 25 days of the huff-n-puff process. On the pressure curve, every peak represents the huff or injection period and every trough represents the puff or production period. We see that within each injection period oil viscosity decreases; within each production period, oil viscosity increases. But oil viscosity progressively decreases with cycles. The oil saturation curve shows 100\% saturation for the first injection cycle of ethane, indicating that ethane behaves like a liquid solvent or liquid oil. However, starting from the second huff-n-puff cycle, we see ethane behaves like a gas to re-vaporize oil. The oil saturation consistently decreases and is eventually zero at the end of 17.5 days.

Similarly, Figure 19 for methane huff-n-puff application shows that the oil saturation decreases with time. However, this decrease is slower in comparison to ethane injection. Even after 25 days the condensate has not completely vaporized. The oil viscosity, on the other hand, shows a slight increase with cycle.

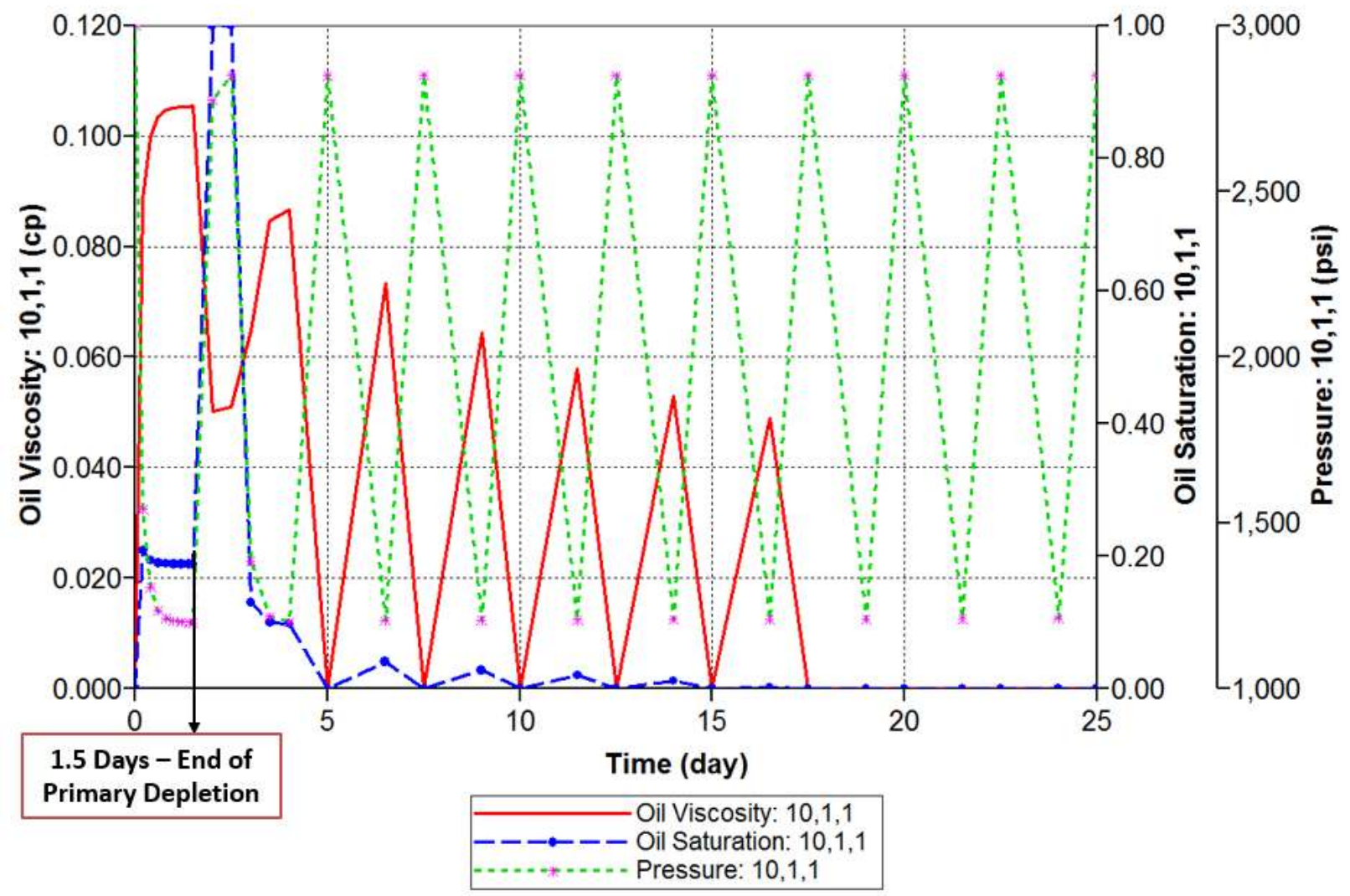

Figure 18: Fluid A, Ethane injection - Changes in oil viscosity, pressure and oil saturation at block $(10,1,1)$ 


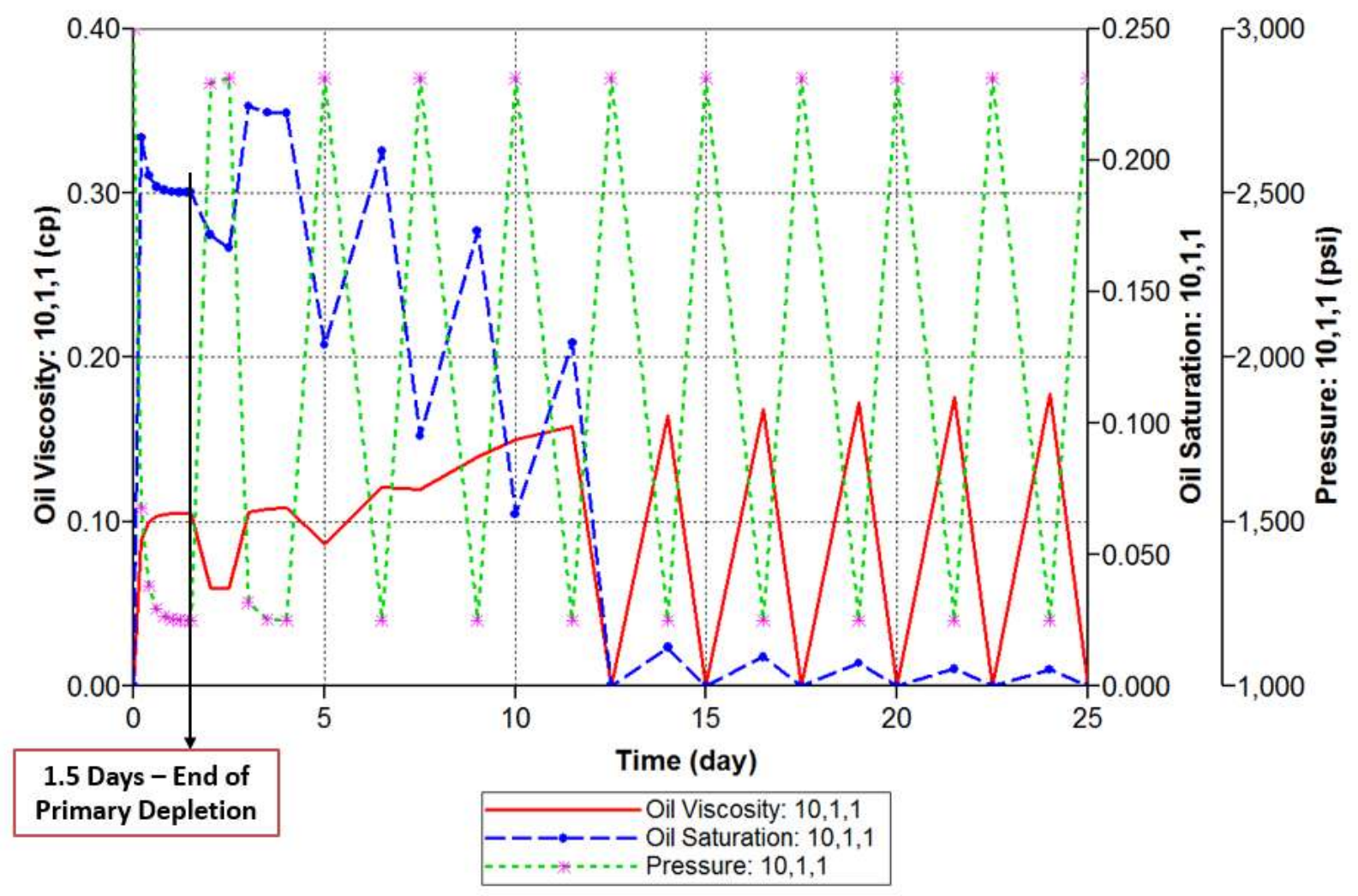

Figure 19: Fluid A, Methane injection - Changes in oil viscosity, pressure and oil saturation at block $(10,1,1)$

First, it is to be noted that the slight increase in oil viscosity for methane injection is observed for the entire time period of huff-n-puff cycles for block $(10,1,1)$. However, for a block location closer to the huff-n-puff well at $(2,1,1)$, oil does not exist (zero oil saturation) after 47.5 days. Thus, no oil viscosity can be presented after this time. Zero oil saturation results from complete condensate re-vaporization near the well. The comparison of the oil viscosity in the two blocks is shown in Figure 20 and 21.

To further comprehend the reason for the slight increase in oil viscosity observed, we plotted the mole fractions of components for the oil phase for block $(2,1,1)$ in Figure 22. The figure shows huff-n-puff time up to 50 days. It is observed that butane is recovered faster relatively to heptane and decane. This can be inferred from the continuous decrease of butane mole fraction, whereas the mole-fractions of heptane and decane which are the heavier components are increasing slightly. This slower recovery of the heavier components is what contributes to the slight increase in oil viscosity.

A similar plot for ethane injection for the same block $(2,1,1)$ shows the in-situ mole fraction of components in the oil phase (Figure 23). It is observed that mole fractions of all three condensate components, i.e., butane, heptane and, decane decreases to zero after two cycles of huff-n-puff. This indicates a superior miscible mechanism to recover the condensate components compared to methane injection. 


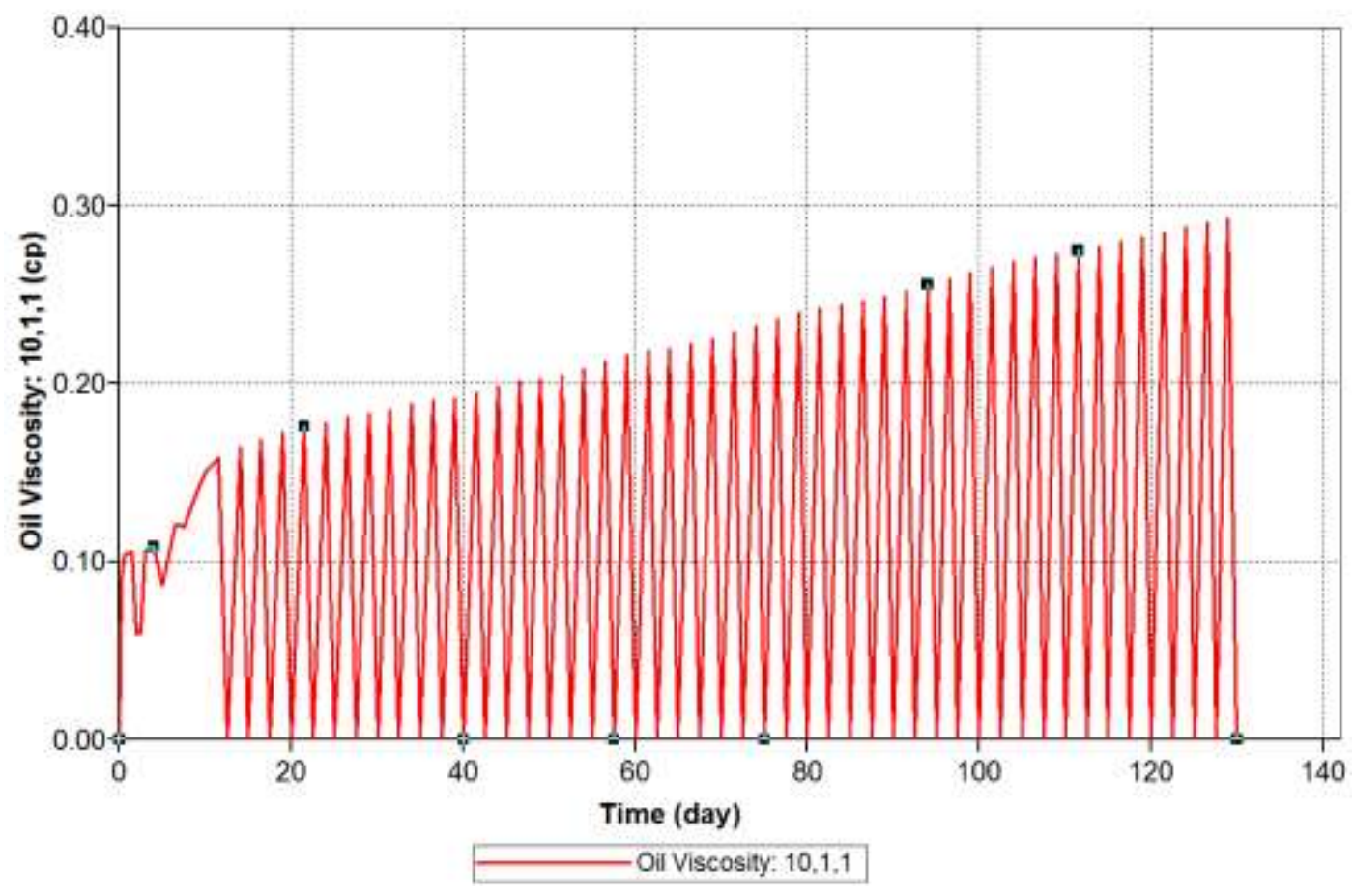

Figure 20: Oil viscosity in block $(10,1,1)$ for methane injection

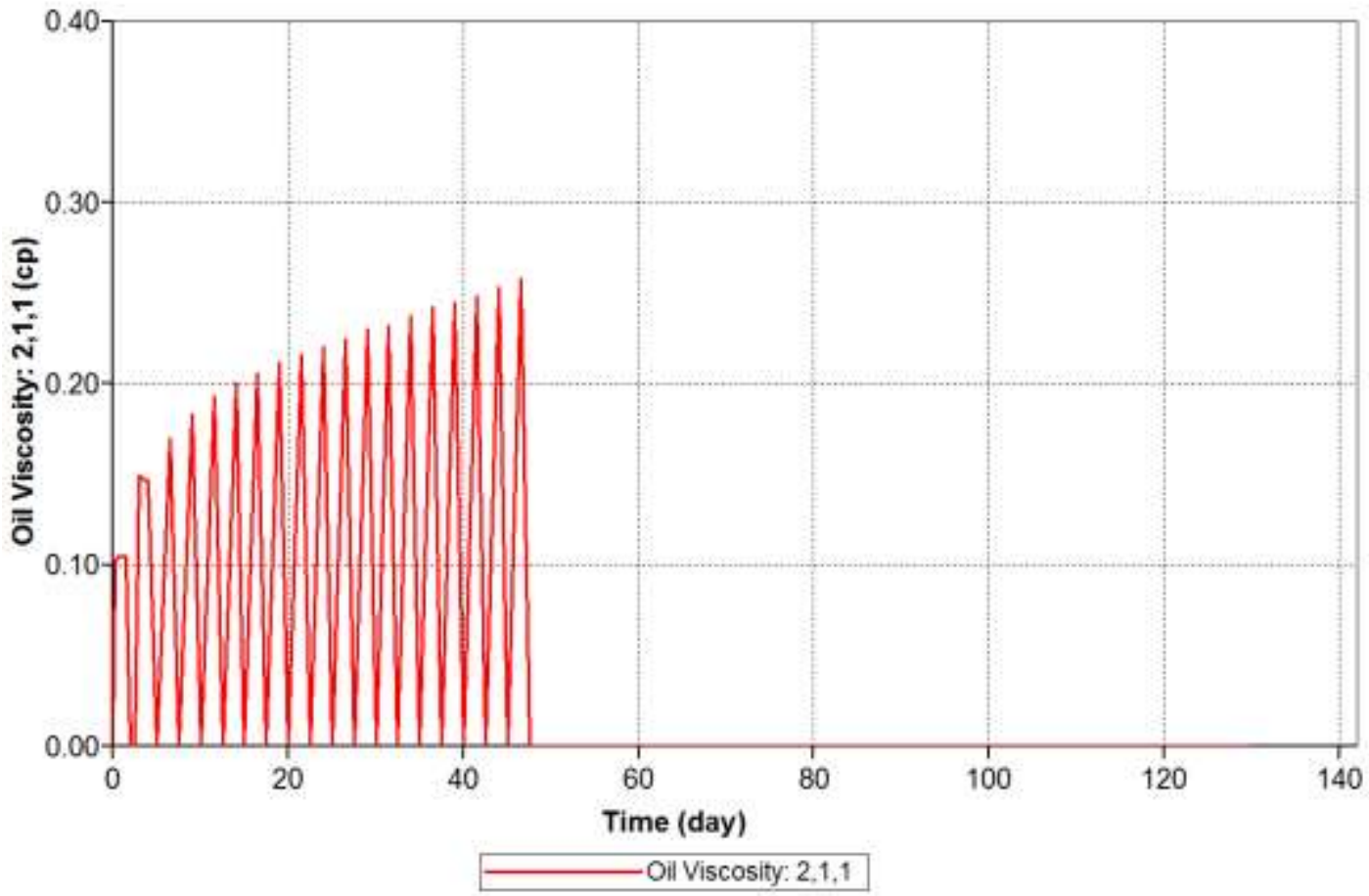

Figure 21: Oil viscosity in block $(2,1,1)$ for methane injection 

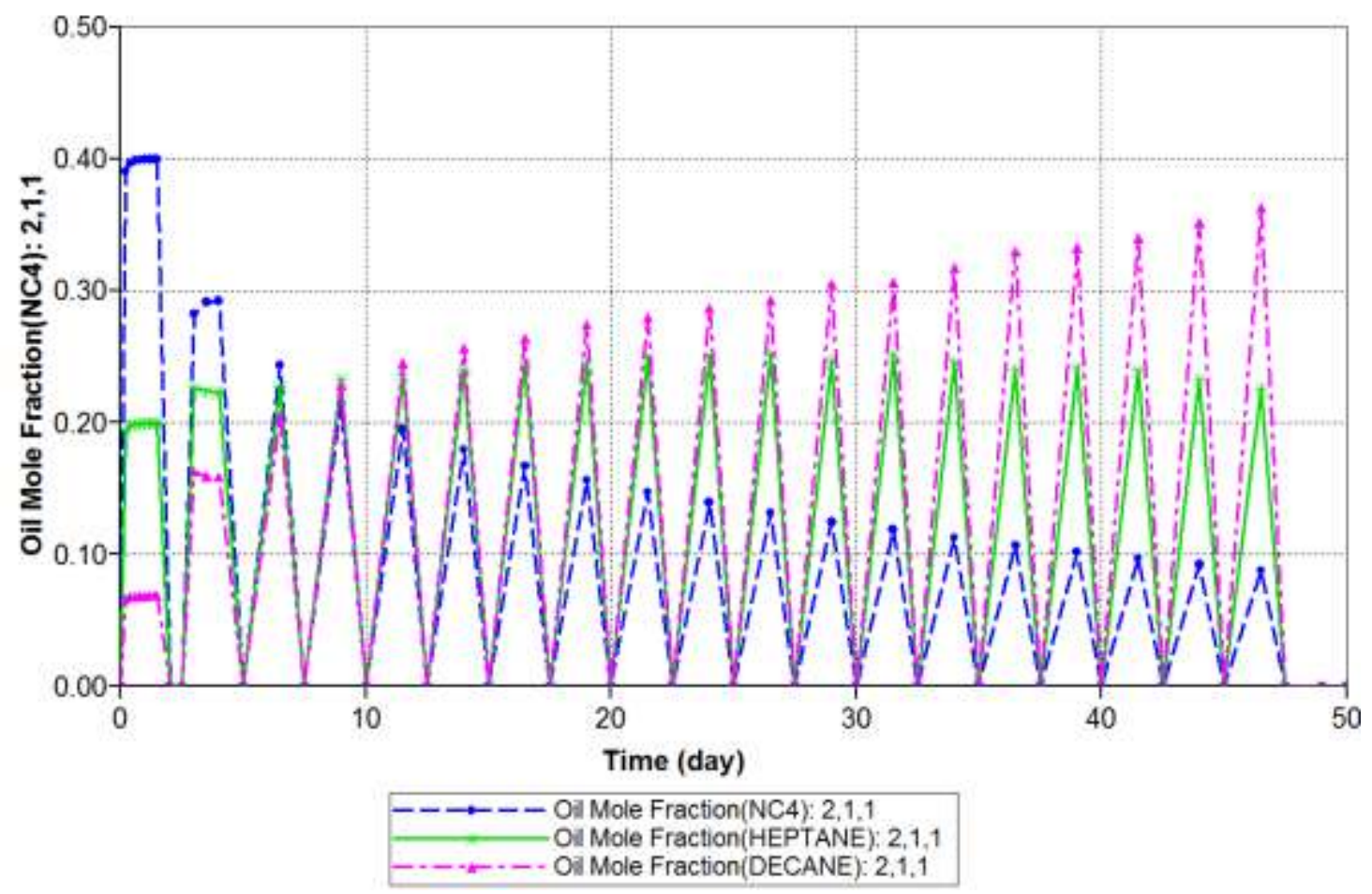

Figure 22: Component mole fractions in block $(2,1,1)$ for methane injection

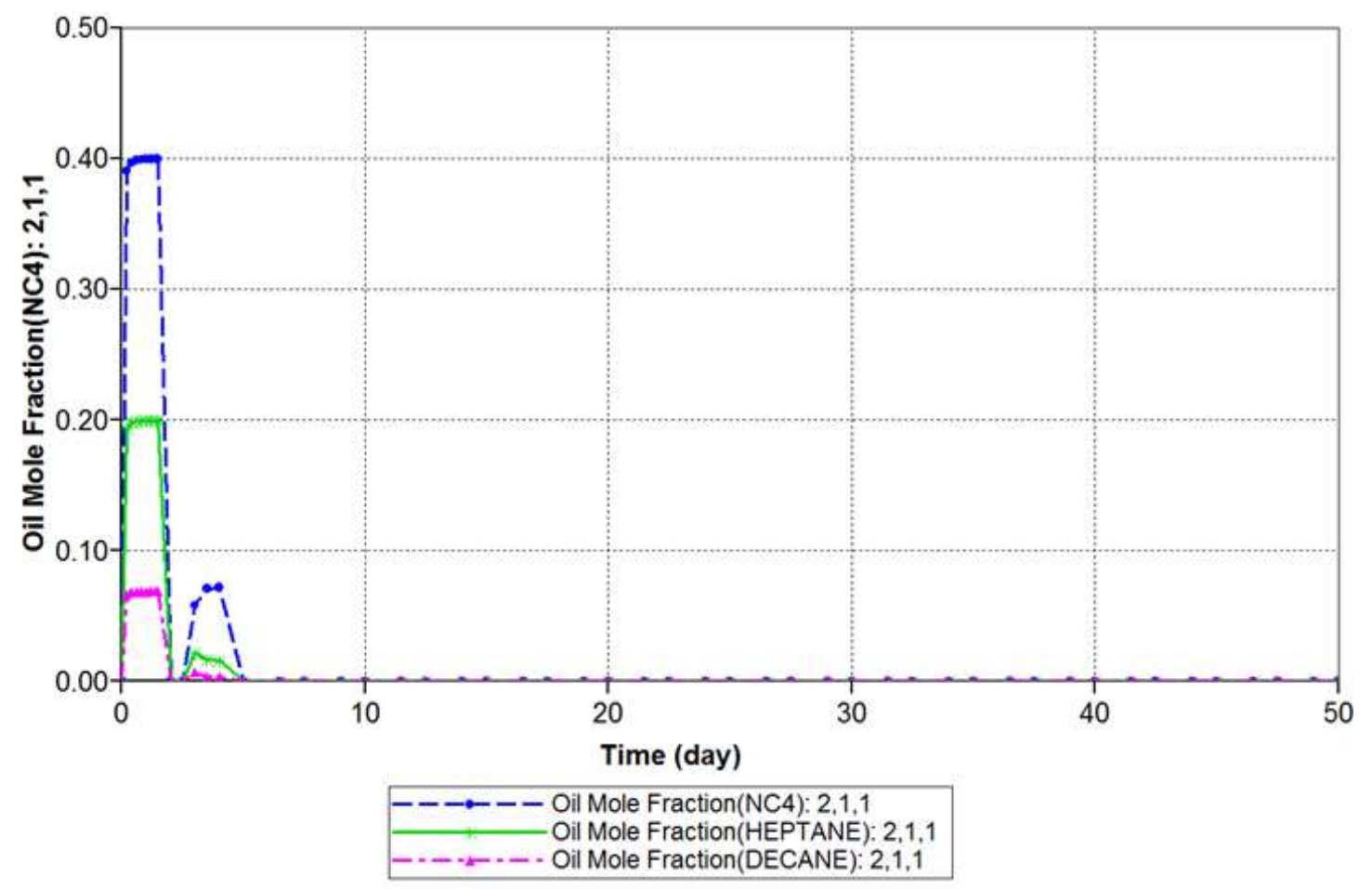

Figure 23: Component mole fractions in block $(2,1,1)$ for ethane injection 


\subsubsection{Solvent (Methanol) and Gas}

Difference in solvent and gas recovery may be attributed to two reasons. First, the mechanism of recovery and, second, the radius of contact of the injected fluids. Methane is able to easily revaporize any dropped out condensate which is produced from the core in the gas phase. Methanol, conversely, solubilizes the condensate and also dissolves some of the in place gas to form a single phase based on reservoir pressure and temperature conditions. Thus, they convert the contacted gas condensate fluid to a volatile oil fluid, which will now have a bubble point instead of a dew point pressure. This can be seen in Figure 24, which shows the oil volume in place in the core after every huff-n-puff injection of methanol, is consistently increasing. The oil volume in place is a mixture of solvent and hydrocarbons.

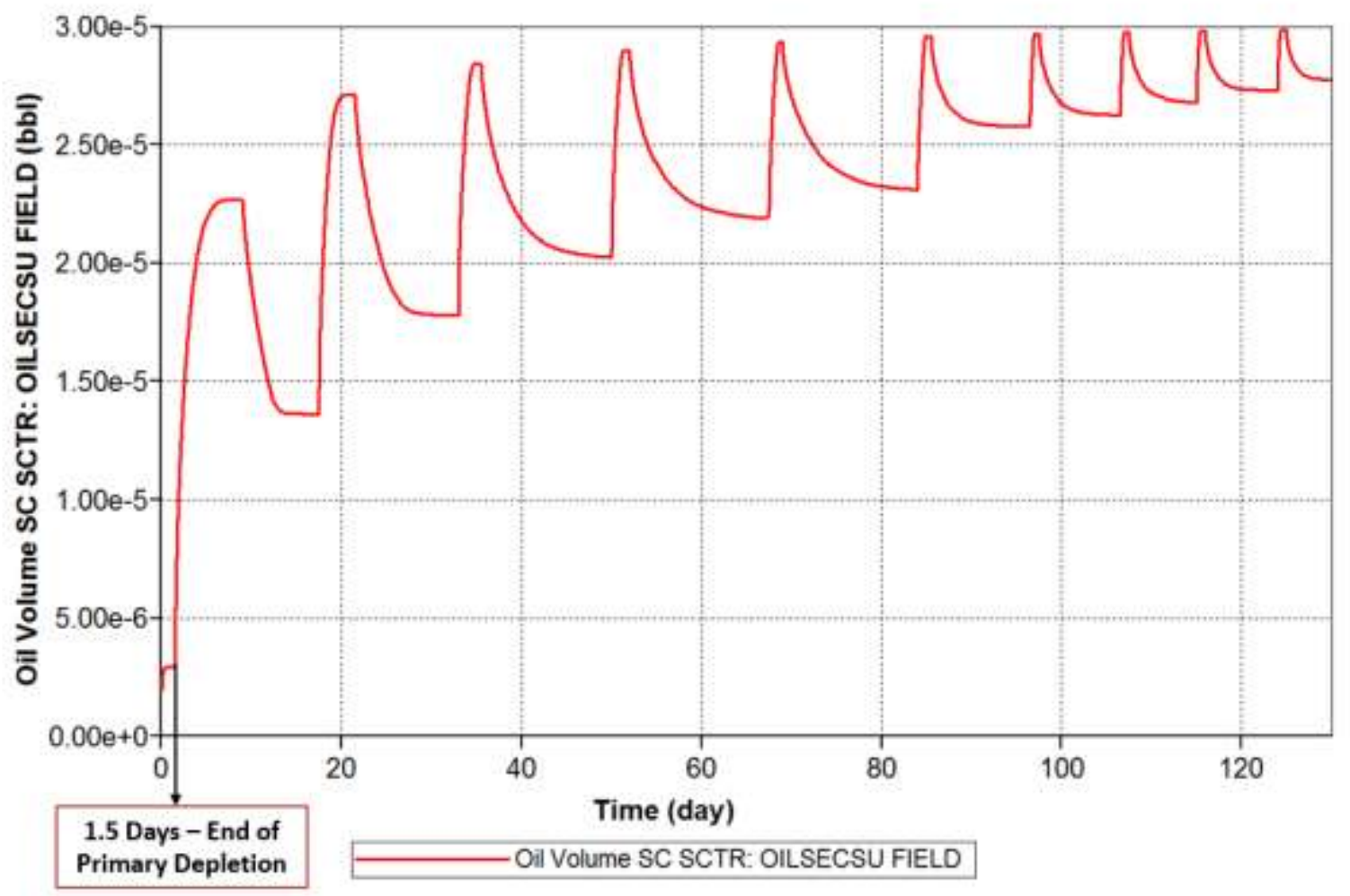

Figure 24: Fluid A, Oil volume in the core after huff-n-puff methanol injection

Secondly, methanol is denser than gas and takes longer to flowback as compared to methane or ethane. This also results in a shorter radius of penetration as compared to the lighter and more volatile fluids such as methane or ethane. This was confirmed by the fact that more cycles of gas huff-n-puff were possible for the same period of time than for methanol. The same is true for initial injection times. Methanol takes a longer time initially to reach injection pressure constraint and penetrate the core as compared to methane and ethane.

Figures 25 and 26 compare methane and methanol injection for pressures in the $4^{\text {th }}$ and $24^{\text {th }}$ block up to 20 days of huff-n-puff cycles. We observe that, for methane, pressure is easily transmitted from the front of the core to the end of the core with the curves almost overlaying 
each other. However, for methanol it takes a much longer time for the solvent to penetrate the core as seen by the time lag between the pressures in block $(4,1,1)$ and block $(24,1,1)$.

Injection time and volume for solvent decrease with subsequent cycles but remain almost the same for methane and ethane. This difference is due to the fact that gases are recovered almost completely and require similar amount of injection volumes for each cycle. However, some amount of methanol remains in the core and thus, it takes lesser volume and time to reach the injection pressure constraint for the next cycles. This is also inferred from Figures 25 and 26.

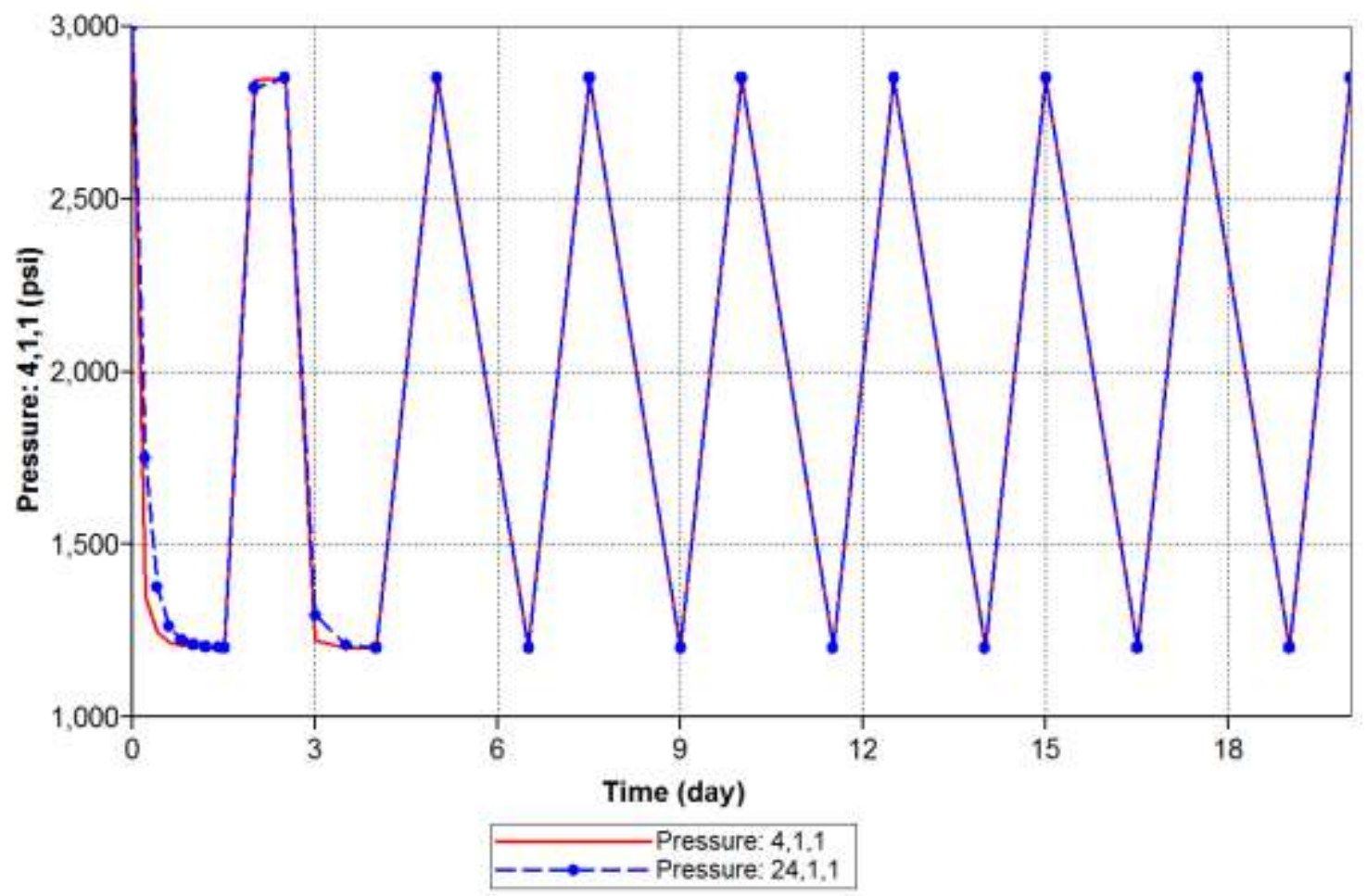

Figure 25: Fluid A, Pressure in the front and end of the core for huff-n-puff of methane injection 


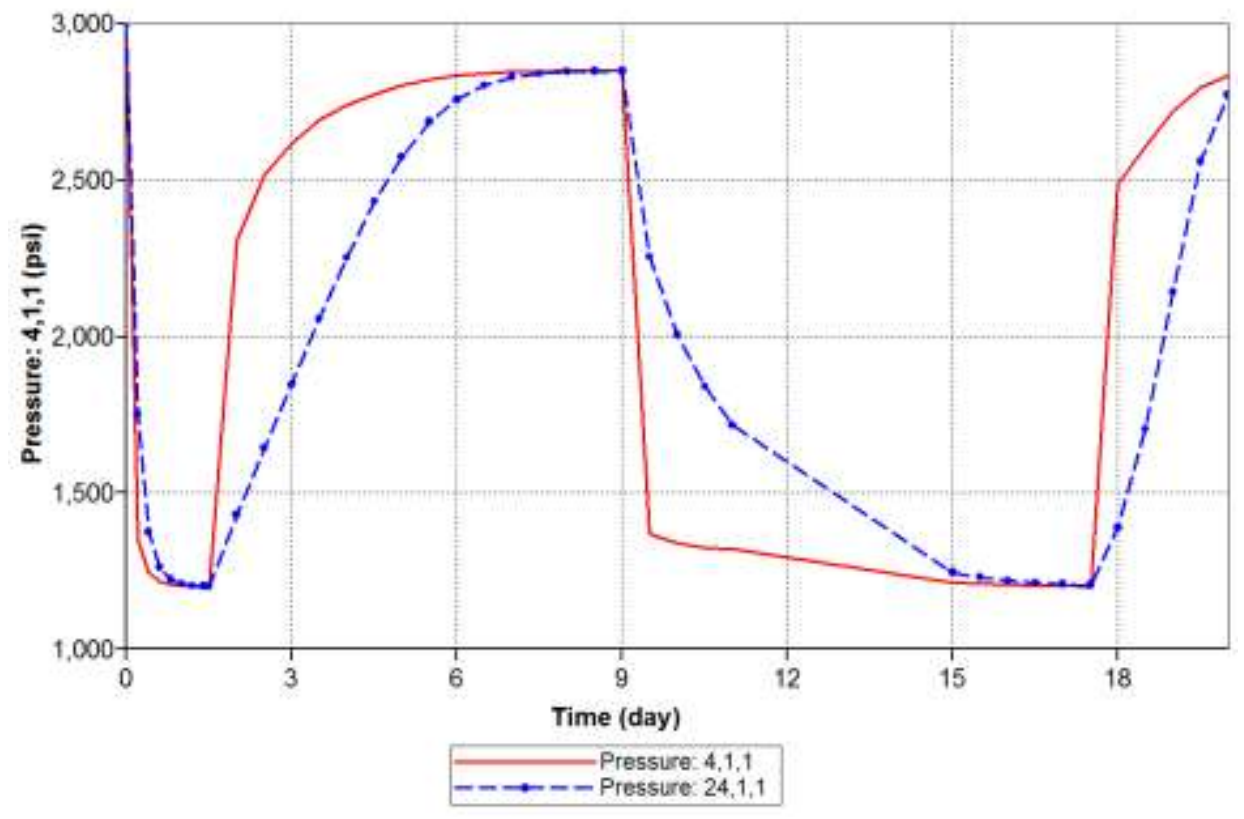

Figure 26: Fluid A, Pressure in the front and end of the core for huff-n-puff of methanol injection

If ethane was assumed to behave like a gas, one would expect its recovery performance to be in between that of methane and the solvents. However, it is to be noted that ethane classifies as a supercritical fluid. A simple phase behavior study shown in Figure 27 reveals that at the given pressure and temperature operating conditions, ethane exists in its supercritical region and exhibits a liquid like state. This was seen in Figure 18, where first cycle of ethane injection resulted in a $100 \%$ liquid saturation due a solvent like behavior. This might mean that ethane huff-n-puff requires a certain concentration of ethane before it can re-vaporize the fluid in place to a gaseous phase and should be investigated in future work.

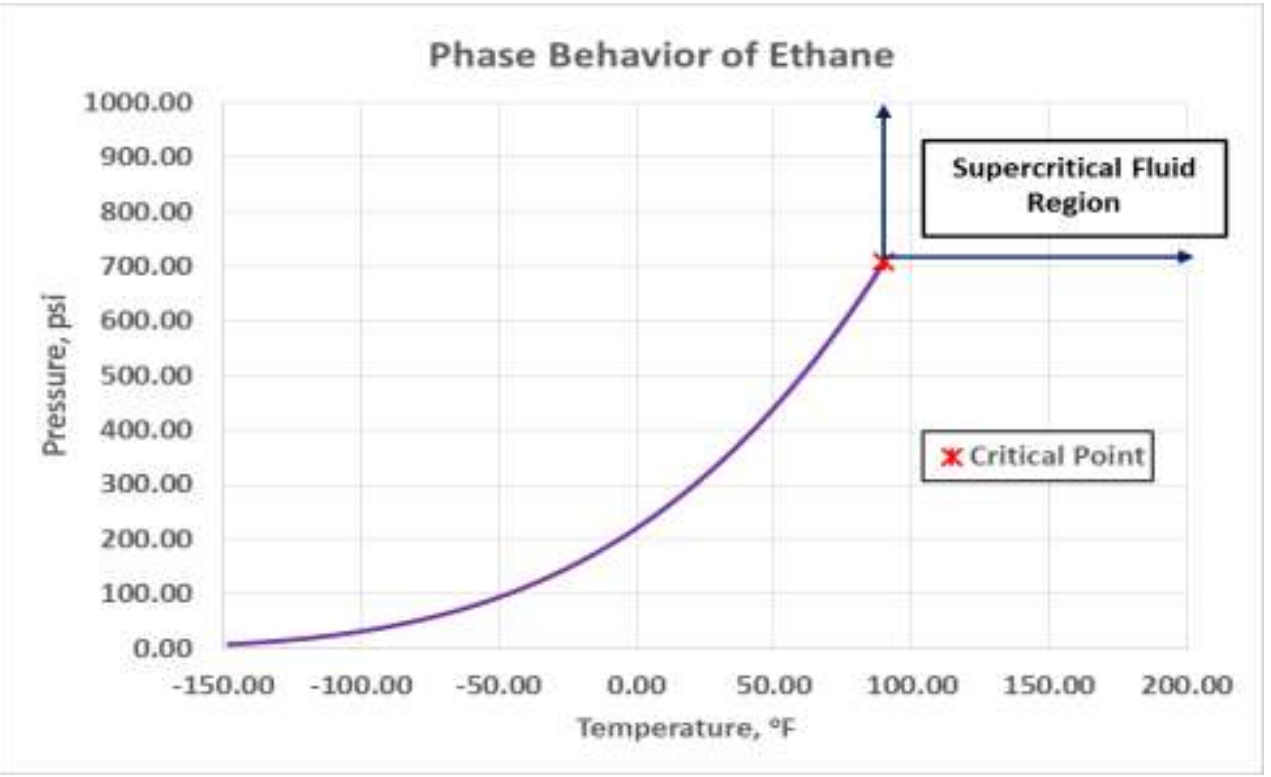

Figure 27: Phase Behavior of ethane and supercritical fluid region 


\section{Conclusions and Remarks}

Ethane proves to be the best injection fluid in recovering the total hydrocarbon in place. It revaporizes condensate and, reduces the dew point pressure of initial reservoir fluid. Its supercritical fluid properties enable it to recover high volumes of the total hydrocarbon fluid in place for small pore volumes of injected fluid. Additionally, it has the added advantage of reducing oil viscosity and enhancing mobility of the condensate.

With a richer composition of a reservoir fluid, the difference in gas and solvent huff-n-puff recoveries is magnified, with significantly higher recovery factors for methane and ethane.

Solvents recover intermediate fluids really well and can be competitive with gas huff-n-puff for lean gas condensate fluids.

Isopropanol is a better solvent than methanol for recovering heavier components, however, high costs may not justify application of isopropanol.

The superior efficiency of ethane to mitigate liquid dropout is based on the simulation work. The results give an insight how ethane can be used as an injection gas for the mitigation purpose. We tried to conduct such experiments but failed because ethane will mix with the condensate making it difficult to split how much condensate can be produced. Our justification of our conclusion or reasoning about the ethane's superior efficiency is that, we history-matched the experiments and simply added ethane in our model; the properties of ethane are well established, and thus our compositional model and the results from this model are justified.

\section{Acknowledgment}

This paper is based upon the work supported by the Department of Energy under Award Number DE-FE00243 11.

\section{References}

Abel, W., Jackson, R.F., Wattenbarger, R.A., 1970. Simulation of a Partial Pressure Maintenance Gas Cycling Project with a Compositional Model, Carson Creek Field, Alberta. JPT, 22(1), 3846.

Afidick, D., Kaczorowski, N.J., Bette, S., 1994. Production Performance of a Retrograde Gas Reservoir: A Case Study of the Arun Field. In: Paper SPE 28749 Presented at the Asia Pacific Oil and Gas Conference, Melbourne, Australia, November 7-10.

Al-Anazi, H.A., Pope, G.A., Sharma, M.M., Metcalfe, R.S., 2002. Laboratory Measurements of Condensate Blocking and Treatment for Both Low and High Permeability Rocks. In: Paper SPE 77546 Presented at the Annual Technical Conference and Exhibition, San Antonio, Texas, 29 September -2 October.

Al-Anazi, H.A., 2003. Experimental Measurements of Condensate Blocking and Treatments in Low and High Permeability Cores. Dissertation, University of Texas at Austin, December. 
Al-Anazi, H.A., Walker, J.G., Pope, G.A., Sharma, M.M., Hackney, D.F., 2003. A Successful Methanol Treatment in a Gas-Condensate Reservoir: Field Application. In: Paper SPE 80901 Presented at the Production and Operations Symposium, Oklahoma City, Oklahoma, March 2225.

Al-Anazi, H.A., Sharma, M.M., Pope, G.A., 2004. Revaporization of Condensate with Methane Flood. In: Paper SPE 90860 Presented at the Annual Technical Conference and Exhibition, Houston, Texas, September 26-29.

Amini, Sh., Aminshahidy, B., Afshar, M., 2011. Simulation Study of Enhanced Condensate Recovery in a Gas-Condensate Reservoir. Iranian Journal of Chemical Engineering, 8(1), 3-14.

Ayyalasomayajula, P., Sharma, R., Walker, J.G., Sharma, M.M., Pope, G.A., 2002. Phase Behavior Modeling of Hydrocarbon-Methanol-Water Mixtures by Peng-Robinson and SAFT Equations of State. In: Paper SPE 77575 Presented at the Annual Technical Conference and Exhibition, San Antonio, Texas, September 2 - October 2, 2002.

Bang, V., 2007. Development of a Successful Chemical Treatment for Gas Wells with Condensate or Water Blocking Damage. Dissertation, University of Texas at Austin, December.

Bang, V., Pope, G.A., Sharma, M.M., Baran Jr., J.R., Ahmadi, M., 2008. A New Solution to Restore Productivity of Gas wells with Condensate and Water Blocks. In: Paper SPE 116711 Presented at the Annual Technical Conference and Exhibition, Denver, September 21-24.

Bang, V., Yuan, C., Pope, G.A., Sharma, M.M., Baran Jr., J.R., Skildum, J.D., Linnemeyer, H.C., 2008. Improving Productivity of Hydraulically Fractured Gas Condensate Well by Chemical Treatment. In: Paper SPE 19599 Presented at the Offshore Technology Conference, Houston, Texas, May 5-8.

Bang, V., Pope, G.A., Sharma, M.M., 2010. Phase Behavior Study of Hydrocarbon/Methanol /Water Mixtures at Reservoir Conditions. In: Paper SPE 102100 Presented at the Annual Technical Conference and Exhibition, San Antonio, Texas, September 24-27.

Bennion, D. B., Mastmann, M., Moustakis, M.L., 2001. Retrograde Condensate Dropout Phenomena in Rich Gas Reservoirs - Impact on Recoverable Reserves and Permeability and Diagnosis and Stimulation Techniques. Petroleum Society's Canadian International Petroleum Conference, Calgary, Alberta, June 12.

DeRuiter, R.A., Nash, L.J., Singletary, M.S., 1994. Solubility and Displacement Behavior of a Viscous Crude With $\mathrm{CO}_{2}$ and Hydrocarbon Gases. In: Paper SPE 20523-PA.

Du, L., Walker, J. G. Pope, G.A., Sharma, M.M., Wang, P., 2000. Use of Solvents to Improve the Productivity of Gas Condensate Wells. In: Paper SPE 62935 Presented at the Annual Technical Conference and Exhibition, Dallas, Texas, October, 1-4.

Ganjdanesh, R., Rezaveisi, M., Pope, G.A., Sepehrnoori, K., 2015. Treatment of Condensate and Water Blocks in Hydraulically Fractured Shale Gas-Condensate Reservoirs. In: Paper SPE 
175145 Presented at the Annual Technical Conference and Exhibition, Houston, Texas, September, 28-30.

Gatlin, C., Slobod, R.L., 1959. The Alcohol Slug Process for Increasing Oil Recovery. In: Paper SPE 1356 Presented at the $34^{\text {th }}$ Annual Fall Meeting of SPE, Dallas, Texas, October 4-9.

Fan, L., Harris, B.W., Jamaluddin, A., Kamath, J., Mott, R., Pope, G.A., Shandrygin, A., Whitson, C.H., 2005. Understanding Gas-Condensate Reservoirs. Oilfield Review, 17(4), 14-27.

McGuire, P.L., Okuno, R., Gould, T.L., Lake, L.W., 2016. Ethane-Based EOR: An Innovative and Profitable EOR Opportunity for a Low Price Environment. In: Paper SPE 179565 Presented at the Improved Oil Recovery Conference, Tulsa, Oklahoma, April 11-13.

Meng, X., Sheng, J. J., 2016. Optimization of Huff-n-Puff Gas Injection in a Shale Gas Condensate Reservoir. Journal of Unconventional Oil and Gas Resources, Vol. 16, 34-44, December.

Meng, X., Sheng, J.J., 2016. Experimental and Numerical Study of Huff-n-Puff Gas Injection to Revaporize Liquid Dropout in Shale Gas Condensate Reservoirs. Journal of Natural Gas Science and Engineering, 35, 444-454.

Meng, X., Sheng, J.J., Yu, Y., 2016. Experimental and Numerical Study on Enhanced Condensate Recovery by Huff-n-Puff Gas Injection in Shale Gas Condensate Reservoirs. SPE Reservoir Evaluation \& Engineering, in press.

Rai, R.R., 2003. Gas Condensates Relative Permeability Parametric Study and Core Flood Simulation. Thesis, University of Texas at Austin, December.

Sheng, J.J. 2015. Enhanced Oil Recovery in Shale Reservoirs by Gas Injection, Journal of Natural Gas Science and Engineering, 22, 252-259.

Sheng, J.J., Mody, F., Griffith, P.J., Barnes, W.N., 2016. Potential to Increase Condensate Oil Production by Huff-n-Puff Gas Injection in a Shale Condensate Reservoir. Journal of Natural Gas Science and Engineering, 28, 46-51.

Siregar, S., Hagoort, J., Ronde, H., 1992. Nitrogen Injection vs. Gas Cycling in Rich Gas Condensate Reservoirs. In: Paper SPE 22360 Presented at the International Meeting on Petroleum Engineering, Beijing, China, March 24-27.

Zhang, H.R., Wheaton, R.J., 2000. Condensate Banking Dynamics in Gas Condensate Fields: Changes in Produced Condensate to Gas Ratios. In: Paper SPE 64662 Presented at the International Oil and Gas Conference and Exhibition, Beijing, China, November 7-10. 